\title{
Direct and semi-direct radiative forcing of biomass-burning aerosols over the southeast Atlantic (SEA) and its sensitivity to absorbing properties: a regional climate modeling study
}

\author{
Marc Mallet ${ }^{1}$, Fabien Solmon ${ }^{2}$, Pierre Nabat ${ }^{1}$, Nellie Elguindi ${ }^{2}$, Fabien Waquet $^{3}$, Dominique Bouniol ${ }^{1}$, \\ Andrew Mark Sayer ${ }^{4,5}$, Kerry Meyer ${ }^{5}$, Romain Roehrig ${ }^{1}$, Martine Michou ${ }^{1}$, Paquita Zuidema ${ }^{6}$, Cyrille Flamant $^{7}$, \\ Jens Redemann ${ }^{8}$, and Paola Formenti ${ }^{9}$ \\ ${ }^{1}$ Centre National de Recherches Météorologiques, UMR3589, Météo-France-CNRS, Toulouse, France \\ ${ }^{2}$ Laboratoire d'Aérologie, UMR 5560, 16 avenue Édouard Belin, 31400 Toulouse, France \\ ${ }^{3}$ Université de Lille, CNRS, UMR 8518, LOA - Laboratoire d'Optique Atmosphérique, 59000 Lille, France \\ ${ }^{4}$ GESTAR, Universities Space Research Association Columbia, MD, USA \\ ${ }^{5}$ NASA Goddard Space Flight Center, Greenbelt, MD, USA \\ ${ }^{6}$ Rosenstiel School of Marine and Atmospheric Sciences, University of Miami, Miami, FL, USA \\ ${ }^{7}$ LATMOS/IPSL, Sorbonne Université, UVSQ, CNRS, Paris, France \\ ${ }^{8}$ School of Meteorology, University of Oklahoma, Norman, Oklahoma, USA \\ ${ }^{9}$ LISA, UMR CNRS 7583, Université Paris Est Créteil et Université Paris Diderot, \\ Institut Pierre Simon Laplace, Créteil, France
}

Correspondence: Marc Mallet (marc.mallet@meteo.fr)

Received: 2 April 2020 - Discussion started: 18 May 2020

Revised: 18 September 2020 - Accepted: 25 September 2020 - Published: 10 November 2020

\begin{abstract}
Simulations are performed for the period 20002015 by two different regional climate models, ALADIN and RegCM, to quantify the direct and semi-direct radiative effects of biomass-burning aerosols (BBAs) in the southeast Atlantic (SEA) region. Different simulations have been performed using strongly absorbing BBAs in accordance with recent in situ observations over the SEA. For the July-August-September (JAS) season, the single scattering albedo (SSA) and total aerosol optical depth (AOD) simulated by the ALADIN and RegCM models are consistent with the MACv2 climatology and MERRA-2 and CAMSRA reanalyses near the biomass-burning emission sources. However, the above-cloud AOD is slightly underestimated compared to satellite (MODIS and POLDER) data during the transport over the SEA. The direct radiative effect exerted at the continental and oceanic surfaces by BBAs is significant in both models and the radiative effects at the top of the atmosphere indicate a remarkable regional contrast over SEA (in all-sky conditions), with a cooling (warming) north (south) of $10^{\circ} \mathrm{S}$, which is in agreement with the recent MACv2 cli-
\end{abstract}

matology. In addition, the two models indicate that BBAs are responsible for an important shortwave radiative heating of 0.5-1 K per day over SEA during JAS with maxima between 2 and $4 \mathrm{~km}$ a.m.s.l. (above mean sea level). At these altitudes, BBAs increase air temperature by $\sim 0.2-0.5 \mathrm{~K}$, with the highest values being co-located with low stratocumulus clouds. Vertical changes in air temperature limit the subsidence of air mass over SEA, creating a cyclonic anomaly. The opposite effect is simulated over the continent due to the increase in lower troposphere stability. The BBA semidirect effect on the lower troposphere circulation is found to be consistent between the two models. Changes in the cloud fraction are moderate in response to the presence of smoke, and the models differ over the Gulf of Guinea. Finally, the results indicate an important sensitivity of the direct and semidirect effects to the absorbing properties of BBAs. Over the stratocumulus $(\mathrm{Sc})$ region, $\mathrm{DRE}$ varies from $+0.94 \mathrm{~W} \mathrm{~m}^{-2}$ (scattering BBAs) to $+3.93 \mathrm{~W} \mathrm{~m}^{-2}$ (most absorbing BBAs). 


\section{Introduction}

In addition to their direct radiative effect (DRE), solar radiation absorbing aerosols (AAs), such as biomass-burning aerosols (BBAs) from vegetation fires and mineral dust from eolian erosion of arid and semi-arid soils, are known to affect regional and global climate through the semi-direct effect (SDE) (Ackerman et al., 2000). The SDE is initiated by modifications in the vertical profile of the shortwave (SW) radiative heating and atmospheric temperature due to the absorption of solar radiation by AAs. Such perturbations in the lower troposphere radiative budget can impact atmospheric vertical stability, circulation and cloud properties. This radiative effect is extremely sensitive to the AA load and vertical distribution in the atmosphere, especially in the presence of cloud layers (Koch and Del Genio, 2010). For instance, AAs can increase the water content of low-level clouds, particularly when AAs are transported above the cloud layer, by stabilizing the free troposphere and increasing the strength of the temperature inversion capping the cloud top, decreasing dry-air entrainment into the low-level clouds (Johnson et al., 2004; Wilcox, 2010; Deaconu et al., 2019; Herbert et al., 2020). Contrarily, when AAs are in contact with low clouds, they may decrease low-cloud cover by heating the air and reducing relative humidity (Hansen et al., 1997; Ackerman et al., 2000).

At the global scale, Perlwitz and Miller (2010) have indicated an increase in low-cloud cover due to mineral dust with increasing aerosol absorption. In addition, results from the Precipitation Driver Response Model Intercomparison Project (PDRMIP) have shown that a 10-fold increase in black carbon (BC) leads to a robust increase in globally averaged low-level clouds and to a reduction in mid-level and high-level clouds (Stjern et al., 2017). Contrarily, based on different global climate models, Allen et al. (2019) find an opposite effect, where a global annual mean decrease in low- and mid-level clouds is associated with weaker decreases in high-level clouds, implying that cloud adjustments act to warm the climate system. Regionally, this study also highlights an important multi-model response found over southern Africa, in which high- and low-level clouds are significantly increased over the continent. In this region, Sakaeda et al. (2011) provided model estimates of regional radiative forcing from direct and semi-direct effects, which have significant impacts on cloud properties by increasing low-cloud cover, notably over the ocean. Randles and Ramaswamy (2010) have also examined the direct and semidirect impacts of absorbing biomass-burning aerosol on the climate of southern Africa using an atmospheric general circulation model. The authors indicate that strong atmospheric absorption from these particles can cool the surface and increase upward motion and low-level convergence over southern Africa during the dry season.

AAs can also impact regional or global atmospheric circulation. In western Africa, Lau et al. (2009) argue that absorb- ing dust can trigger the elevated heat pump effect, impacting the African monsoon dynamics and Sahel precipitation. In the same region, Solmon et al. $(2008,2012)$ also demonstrated the sensitivity of monsoon dynamics and precipitation to AA (mineral dust) optical properties. Several studies conducted during the Indian Ocean Experiment (INDOEX) and Aerosol Characterization Experiment (ACE) Asia projects have also demonstrated that polluted aerosols containing $\mathrm{BC}$ could affect the regional circulation and hydrological cycle over the Indian and Asian regions (Ramanathan et al., 2001; Lau et al., 2006; Bollasina et al., 2014). These changes have also been found to be strongly related to the absorbing vs. diffusive nature of anthropogenic aerosols. Over tropical Africa, Tosca et al. (2015) indicate a reduction in cloud fraction during periods of high aerosol optical depths related to a smokedriven inhibition of convection.

BBAs represent one of the main aerosol species able to induce a significant SDE at regional and global scales. Due to the large fraction of $\mathrm{BC}$ within the smoke plumes, BBAs absorb SW radiation and are characterized by a single scattering albedo (SSA) significantly lower than unity (Dubovik et al., 2002). From Aerosol Robotic Network (AERONET) retrievals in Zambia, Eck et al. (2013) reported SSA between 0.80 and 0.86 (at $550 \mathrm{~nm}$ ) during the biomass-burning season, with minima in July. During SAFARI-2000 (South Africa), Leahy et al. (2007) indicate a "campaign-average" SSA $(550 \mathrm{~nm})$ of $0.85 \pm 0.02$. Over western Africa, Johnson et al. (2008) reported SSA from 0.73 to $0.93(550 \mathrm{~nm})$ in aerosol layers dominated by biomass burning during the Dust and Biomass-burning Experiment (DABEX) campaign, while values of 0.79 and 0.88 have been obtained over different regions in South America (Darbyshire et al., 2019). Over the SEA, Pistone et al. (2019) report that the ORACLES2016 measured or retrieved SSA (at $500 \mathrm{~nm}$ ) ranges between 0.85 and 0.88 , depending on the instrument used.

Interestingly, recent observations obtained during the LASIC project (Zuidema et al., 2016) measured extremely low SSA $(\sim 0.75$ at $550 \mathrm{~nm})$ for aged BBAs at Ascension Island (Zuidema et al., 2018), similar to values reported by Denjean et al. (2020) for smoke aerosols transported over the Gulf of Guinea during the DACCIWA experiment (Flamant et al., 2018). Such low values are consistent with recent findings obtained during the Clouds and Aerosol Radiative Impacts and Forcing (CLARIFY) project (Wu et al., 2020). The possible mixing state (external or internal) of $\mathrm{BC}$ particles contained within smoke plumes, combined with photochemical oxidation (Wu et al., 2020) and loss of organic aerosol during transport, represents possible processes explaining such low values. These recent outstanding absorbing properties of BBAs measured over the SEA, associated with the important loading of smoke particles transported above Sc in the SEA (Sayer et al., 2019; Kacenelenbogen et al., 2019; Mallet et al., 2019), could have important implications in terms of direct and semi-direct radiative effects. Quantifying these impacts 
and related feedbacks at the climatic timescale is one of the main objectives of the present study.

Until now, most studies have focused on specific events. For example, Lu et al. (2018) quantified an average SDE plus DRE of $-1.0 \mathrm{~W} \mathrm{~m}^{-2}$ for a 2-month large-eddy simulation over SEA, which is significantly smaller than the indirect forcing $\left(-7.0 \mathrm{~W} \mathrm{~m}^{-2}\right)$. Gordon et al. (2018) investigated a $10 \mathrm{~d}$ case study during August 2016 using the HadGEM global climate model at convection-permitting spatial resolution. They indicate a substantial positive DRE $\left(+11 \mathrm{~W} \mathrm{~m}^{-2}\right)$ at the regional scale associated with important $\operatorname{SDE}\left(-30 \mathrm{~W} \mathrm{~m}^{-2}\right)$ and indirect forcing $\left(-10 \mathrm{~W} \mathrm{~m}^{-2}\right)$. In that study, the microphysical and dynamical changes led to an increase in liquid water path (LWP) relative to a simulation without BBAs. Finally, recent field measurements obtained at Ascension Island reveal that the low-cloud fraction (LCF) decreases with enhanced smoke loadings within the boundary layer, suggesting a positive feedback of SDE (Zhang and Zuidema, 2019). To our knowledge, Sakeada et al. (2011) and Allen et al. (2019) are the only studies which have investigated the DRE/SDE of BBAs at a climatic scale using global atmospheric models.

This study investigates these radiative effects over SEA at a climatic scale. Two independent regional climate models (RCMs) are employed for assessing the robustness of the results. We specifically investigate the SDE of BBAs on the dynamics of the lower troposphere over SEA for the period 2000-2015, as well as the induced changes on low-cloud properties. We also propose the first set of long-term simulations of both DRE and SDE using extreme absorbing properties of BBAs based on recent in situ observations (Zuidema et al., 2018; Denjean et al., 2020; Wu et al., 2020) obtained over the tropical African region. In this context, the main scientific questions are the following:

- What is the shortwave DRE of BBAs at the surface and at the top of the atmosphere (TOA) in all-sky conditions over SEA and central Africa?

- How strong is the induced SW heating of BBAs and what are its impacts on the atmospheric temperature profile?

- What is the impact of the SDE of BBAs on the lower troposphere circulation and Sc properties?

- What is the sensitivity of DRE and SDE to smokeabsorbing properties?

To address these scientific questions, this study is organized as follows. Section 2 describes the different simulations and the data sets used for the model evaluation. Section 3 evaluates the representation of the SEA mean climate, as well as Sc and BBA optical properties. Sections 4 and 5 quantify the DRE (at the surface and TOA) and SDE (on the lower troposphere atmospheric circulation and low-cloud properties) of smoke particles, respectively. Finally, Sect. 6 investigates the sensitivity of both forcing effects to BBA absorbing properties. Conclusions are given in Sect. 7.

\section{Methodology}

\subsection{Models and simulations}

\subsubsection{ALADIN and RegCM}

This study relies on two regional climate models, namely CNRM-ALADIN63 and RegCM, described by Nabat et al. (2020) and Giorgi et al. (2012), respectively. Both models are driven by the ERA-Interim (ERAI) reanalysis over a period covering 2000-2015 (ALADIN) and 20032015 (RegCM). Sea surface temperatures (SSTs) are prescribed for ALADIN, whereas RegCM uses a slab ocean approach described in Solmon et al. (2015). It should be noted that prescribed SST can also be altered by the aerosol radiative effect. Different domains and spatial resolutions have been considered (see Table 1). ALADIN uses a $12 \mathrm{~km}$ horizontal resolution with 91 vertical levels (from 1015 to $0.01 \mathrm{hPa}$ ), focusing on a southern Africa domain, while RegCM uses an $80 \mathrm{~km}$ horizontal resolution (with 42 vertical levels up to $50 \mathrm{hPa}$; see Table 1) on a large pan-African domain (latitude: $-35^{\circ} \mathrm{S}$ to $30^{\circ} \mathrm{N}$; longitude: $-30^{\circ} \mathrm{W}$ to $45^{\circ} \mathrm{E}$ ). In ALADIN, the possible long-range transport of BBAs is not forced at the lateral boundary conditions, but the rather large domain (latitude: $-37.1^{\circ} \mathrm{S}$ to $09.4^{\circ} \mathrm{N}$; longitude: $-33.4^{\circ} \mathrm{W}$ to $45.4^{\circ} \mathrm{E}$ ) encompasses the main biomassburning sources. Land surface processes are treated using the SURFEX (Surface Externalisée) model (Masson et al., 2013; Decharme et al., 2019). In RegCM, chemical boundary conditions are given by monthly aerosol fields derived from an EC-EARTH-CAMS global simulation. CLM45 is used as the land surface scheme and the Tiedke scheme is used for convection. Of primary importance, we use the University of Washington planetary boundary layer turbulence scheme, which has been evaluated over the Californian region by O'Brien et al. (2012), showing a notable improvement in the representation of low Sc. The rapid radiative transfer model (RRTM) scheme is used to calculate interactions between aerosol radiative properties and shortwave and longwave (LW) radiation (for coarse dust and sea-salt particles).

Finally, the statistical cloud parameterization used in ALADIN is based on the work of Sommeria and Deardorff (1977) and Bougeault (1981) and coupled to the turbulence scheme (Cuxart et al., 2000) to derive subgrid-scale variances. This is fully described in Roehrig et al. (2020). In RegCM, the convective cloud fraction is parameterized according to selected convective schemes, while cloud water content is estimated depending on a temperature-based parameterization (Giorgi et al., 2012). Subgrid cloud fractions and cloud water content are combined to resolved cloud frac- 
Table 1. RegCM and ALADIN regional climate model configurations.

\begin{tabular}{|c|c|c|}
\hline & ALADIN & RegCM \\
\hline Horizontal resolution & $12 \mathrm{~km}$ & $80 \mathrm{~km}$ \\
\hline Number of vertical level & 91 & 42 \\
\hline Emissions & $\begin{array}{l}\text { GFED (monthly) } \\
\text { van Marle et al. (2017) }\end{array}$ & $\begin{array}{l}\text { GFED (daily) } \\
\text { van Marle et al. (2017) }\end{array}$ \\
\hline Scale factor & 1.5 for $\mathrm{OC}$ and $\mathrm{BC}$ & 1.5 for $\mathrm{OC}$ and $\mathrm{BC}$ \\
\hline Aerosol types & $\begin{array}{l}\text { Mineral dust, primary sea spray, } \\
\text { biomass burning, anthropogenic } \\
\left(\mathrm{BC}, \mathrm{OC}, \mathrm{SO}_{4}\right)\end{array}$ & $\begin{array}{l}\text { Mineral dust, primary sea spray, } \\
\text { biomass burning, anthropogenic } \\
\left(\mathrm{BC}, \mathrm{OC}, \mathrm{SO}_{4}\right)\end{array}$ \\
\hline $\begin{array}{l}\text { Mixing assumption } \\
\text { (optical calculations) }\end{array}$ & External & External \\
\hline $\begin{array}{l}\text { BBA SSA for sensitivity } \\
\text { experiments (at } 550 \mathrm{~nm} \text { ) }\end{array}$ & $\begin{array}{l}0.75 \text { (SMK_75) } \\
\text { and } 0.90 \text { (SMK_90) }\end{array}$ & $\#$ \\
\hline Aerosol boundary conditions & No & Yes (CAMS) \\
\hline Ocean-atmosphere coupling & $\begin{array}{l}\text { No } \\
\text { (prescribed SST) }\end{array}$ & $\begin{array}{l}\text { Yes } \\
\text { Slab ocean model }\end{array}$ \\
\hline Radiative transfer scheme & FMR (SW)/RRTM (LW) & RRTM (SW and LW) \\
\hline Period of simulations & $2000-2015$ & 2003-2015 \\
\hline
\end{tabular}

\# means there are no sensitivity tests in RegCM.

tion and water content before being passed to the radiation scheme.

\subsubsection{Aerosol schemes}

The aerosol schemes of the two models are quite similar in terms of complexity and compatible with climate-scale integrations. In ALADIN, the TACTIC (Tropospheric Aerosols for ClimaTe in CNRM) aerosol scheme accounts for sulfate, organic (OC) and black (BC) carbon, dust, and primary seasalt particles (Nabat et al., 2015; Michou et al., 2015, 2020; Mallet et al., 2019). In RegCM, the option used here is described in Solmon et al. (2006), Tummon et al. (2010) and Malavelle et al. (2011), with a special treatment for biomassburning aerosol described through a "smoke" tracer as described in Sect. 2.1.3. In both models, mineral dust and seasalt emissions are interactively connected with surface meteorological fields and soil properties (Nabat et al., 2015; Solmon et al., 2008, 2012). The emission of mineral dust is primarily taken into account following Marticorena and Bergametti (1995), while the current formulation for primary sea spray is based on Grythe et al. (2014) for ALADIN and Zakey et al. (2008) for RegCM. These models include tracer advection by atmospheric winds, diffusion by turbulence and surface emissions, and dry and wet (in-cloud and belowcloud) removal processes. In both RCMs, a bulk approach is applied for primary BC, OC and sulfate, whereby a fixed aerosol size distribution is assumed for calculating aerosol properties. In the two models, a more resolved size distribution ( 6 or 12 fixed bins) is used for primary mineral dust and sea-salt particles.

Both models assume external mixing of the different aerosol species, which could potentially be a limitation, especially with regard to possible OC-BC mixing (internal and external) state, which can significantly affect SW absorption (Fierce et al., 2016). Knowing that, specific attention is given to the evaluation of the simulated single scattering albedo of BBAs in this study. The radiative properties (mass extinction efficiency, SSA and asymmetry parameter) of each aerosol species are calculated for the different spectral bands of the Fouquart and Morcrette radiation scheme (FMR; Morcrette, 1989) and the RRTM (Mlawer et al., 1997) for SW and LW radiation respectively, as well as in ALADIN-Climat and RRTM for RegCM (see Table 1). Aerosol forcing at the surface and TOA in SW and LW spectral ranges, in both clearsky and all-sky conditions, are diagnosed using a double call to the radiation schemes during the model integration. The DRE is calculated following Ghan (2013).

\subsubsection{Representation of BBAs}

Following Mallet et al. (2017, 2019), two tracers have been implemented in both regional models describing the mass concentration of fresh (less hygroscopic) and aged (more 
hygroscopic) smoke aerosols. This method allows distinguishing between aerosols from biomass burning and anthropogenic emissions and allows specific properties to be monitored, such as $e$-folding time and hygroscopic and optical properties. Although many GCMs represent BBAs as separate components (BC and $\mathrm{OC}$ ), this approach allows the representation of BBAs as a single species including fresh and aged modes, making comparisons using aircraft and remotesensing observations that characterize the ambient BBAs rather than $\mathrm{BC}$ and $\mathrm{OC}$ components more straightforward. With this approach, the BBA aerosol model properties can still be adjusted and/or evaluated using regional experimental campaigns over SEA such as ObseRvations of Aerosols above Clouds and their intEractionS (ORACLES; Redemann et al., 2020), Aerosol RadiatiOn and CLOuds in southern Africa (AEROCLO-sA; Formenti et al., 2019) or CLARIFY.

In both models, aging from the fresh (hydrophobic) to (hygroscopic) aged mode is quantified using an $e$-folding time of $6 \mathrm{~h}$ according to Abel et al. (2003). This value is 2 times higher than the $\sim 3 \mathrm{~h}$ recently proposed by Vakkari et al. (2018) for the southern African savannah. While analysis of BBA chemical composition and optical or hygroscopic properties from the recent field campaigns are ongoing, preliminary results from Ascension Island indicate that atmospheric aging increases the ability of smoke to act as cloud condensation nuclei and to absorb SW radiation (Zuidema et al., 2018). Finally, for each BBA tracer, log-normal drystate aerosol size distributions and refractive indices are assumed following Mallet et al. $(2017,2019)$ to calculate radiative properties for "fresh" and "aged" smoke tracer. As BBAs are known to be hydrophilic (Rissler et al., 2006), the dependence of the radiative properties on relative humidity $(\mathrm{RH})$ has been included for both tracers following Mallet et al. $(2017,2019)$.

\subsubsection{ALADIN and RegCM experiment design}

In this study, four ALADIN-Climat and two RegCM simulations have been performed (Table 1). The RegCM and ALADIN control runs (CTL) do not take BBAs into account so that all aerosols are activated and interactive with radiation (i.e., direct and semi-direct effects for those particles are included), but biomass-burning emissions are set to zero. The perturbed simulations (termed SMK) include the smoke emissions and the direct and semi-direct radiative effects of BBAs. In this study, we reiterate that the first indirect radiative effect of BBAs is not included and the cloud droplet effective radius is fixed $(10 \mu \mathrm{m})$. Finally, in order to test the sensitivity of DRE and SDE to the BBA absorbing aerosols, two additional simulations, namely SMK_90 and SMK_75, have been performed with the ALADIN model using directly fixed SSA of respectively 0.90 and 0.75 (at $550 \mathrm{~nm}$ ) in the model. As mentioned in the introduction, the simulations using enhanced absorbing properties of BBAs are motivated by recent studies showing very low SSA for an aged BBA plume emitted from central Africa (Zuidema et al., 2018; Denjean et al., 2020; Wu et al., 2020).

Global Fire Emissions Database version 4 (GFED) biomass-burning emissions (van Marle et al., 2017) are prescribed in both models. The GFED is based on estimates of burned area, active fire detections, and plant productivity derived from MODIS. Carbon emission fluxes are converted to trace gas and aerosol emissions using species-specific emission factors based on Andreae and Merlet (2001). Monthlymean GFED emissions are used in ALADIN, while RegCM is forced by daily mean emissions. In all experiments, the BBA emissions have been scaled up by a factor of 1.5 for BC and $\mathrm{OC}$, which is a common practice in climate modeling studies for BBAs (Pan et al., 2020). This factor is fairly consistent with Thornhill et al. (2018), who consider a factor of 2 in the HadGEM climate model in order to reproduce observed satellite AODs over South America. Reddington et al. (2016) indicate that multiple modeling studies have used factors up to 6 to correctly represent observed BBA AOD from emission inventories. Johnson et al. (2016) have indicated that many studies (Marlier et al., 2013; Petrenko et al., 2012; Tosca et al., 2013) have also used emission factors higher than 1.

BBAs are emitted into the first vertical level of each model, without any consideration of pyroconvective processes, as there is no clear consensus on such processes or typical injection heights over this region. For example, Labonne et al. (2007) showed that emitted smoke plumes are generally confined to the boundary layer close to the main biomassburning source regions. Menut et al. (2018) have tested different forms of injection profiles and have shown that injection of BBAs above the boundary layer did not significantly change the impact on air quality for cities in the Gulf of Guinea region when compared to BBAs being injected in the boundary layer. In the simulation, fire emissions from the savannah are also emitted at the lowest model level and efficiently mixed by subgrid-scale turbulence through the boundary layer. Even if the raw GFED has $3 \mathrm{~h}$ intervals, the diurnal cycle of smoke emission is also not taken into account, which could impact the temporal variations of the aerosol loadings (Xu et al., 2016).

\subsection{Data}

\subsubsection{Radiation and surface temperature data}

In order to evaluate the performance of both models, we use several data sets from ground-based measurements and satellite products. The Climatic Research Unit (CRU) of the University of East Anglia provides $2 \mathrm{~m}$ temperature and precipitation at a $0.5^{\circ} \times 0.5^{\circ}$ resolution (Harris et al., 2013). It includes most of the land weather stations data around the world. In addition, we used the EUMETSAT CM-SAF Surface Solar Radiation Parameters (SARAH-2), which comprises five parameters related to 
surface solar irradiance, including surface incoming shortwave radiation (SIS). These are derived from the geostationary first-generation (Meteosat-MVIRI) and secondgeneration (Meteosat-SEVIRI) satellite sensors. The data set covers Africa, Europe and most of the Atlantic Ocean. Finally, we have also used the buoy observing system Pilot Research Moored Array in the Tropical Atlantic (PIRATA) (Bourlès et al., 2019) for downwelling shortwave radiation in the tropical Atlantic Ocean.

\subsubsection{Cloud and aerosol reanalysis data}

In this study, we used cloud products (liquid water path and cloud fraction) from the ERAI global atmospheric reanalysis (Dee et al., 2011) provided by the European Centre for Medium-Range Weather Forecasts (ECMWF). ERAI covers the period from 1979 onwards and has been continuously extended operationally until August 2019. The ERAI reanalysis is produced by the Integrated Forecast System (IFS), which includes the forecast model consisting of three fully coupled components for the atmosphere, land surface and ocean waves. ERAI clouds are represented by a fully prognostic cloud scheme in which cloud-related processes are treated in a unified way; i.e., they are physically realistic and consistent with the rest of the model. Clouds are defined by the horizontal coverage of the grid box by cloud and the mass mixing ratio of total cloud condensate, along with the constraint that cloud air is saturated with regard to liquid water and ice. ERAI in general has been used in many climate studies in the past, including cloud studies (e.g., Jiang et al., 2011).

Two different reanalysis products are used to evaluate aerosols. The ECMWF reanalysis of global atmospheric composition includes five main aerosol species. In this work, we use the recent CAMS-RA aerosol reanalysis (Inness et al., 2019) for the total AOD. In addition, we use Modern-Era Retrospective analysis for Research and Applications version 2 (MERRA-2), generated with version 5.2.0 of the Goddard Earth Observing System atmospheric model and data assimilation system (Randles et al., 2017). We rely on the AOD for the different species at $0.5^{\circ} \times 0.625^{\circ}$ spatial resolution. In addition, and more specifically for the absorbing properties, we have used the recent MACv2 aerosol climatology in its second version (Kinne, 2019), which provides monthly global fields of optical properties at $1^{\circ} \times 1^{\circ}$ spatial resolution, derived from a combination of observations (notably from the AERONET network) and model outputs. The aerosol climatology is the merging of monthly statistics of aerosol optical properties with a central reference year for 2005 conditions.

\subsubsection{Cloud and aerosol satellite data}

Spatiotemporally highly $\left(0.05^{\circ} \times 0.05^{\circ}\right)$ resolved geostationary satellite observations are taken here from the CLoud property dAtAset based on SEVIRI edition 2 (CLAAS-2; Benas et al., 2017). The CLAAS-2 data set is based on mea- surements of the Spinning Enhanced Visible and Infrared Imager (SEVIRI) and was generated and released by the EUMETSAT Satellite Application Facility on Climate Monitoring (CM SAF). CLAAS-2 includes a variety of cloud properties, including LWP, cloud optical depth and effective radius. The CLAAS-2 level 2 data are instantaneous data on native SEVIRI resolution with a temporal resolution of $15 \mathrm{~min}$. For this study, the data are projected onto a regular latitude-longitude grid using the nearest-neighbor approach. It should be noted that Sc cloud retrievals could be affected by the presence of BBAs over the SEA. Recently, Seethala et al. (2018) indicated that, in the aerosol-affected months of July, August and September, SEVIRI liquid water path is biased by $\sim 16 \%$.

In addition, the cloud cover has been also documented using observations from the Cloud Aerosol Lidar with Orthogonal Polarization (CALIOP, Winker et al., 2007) lidar on board CALIPSO. The cloud cover is computed on an instantaneous basis from the CALIPSO Vertical Feature Mask version 4.20 (Vaughan et al., 2009), which provides a cloud mask on a high-resolution grid up to $8.2 \mathrm{~km}$, and an intermediate resolution grid ( $1 \mathrm{~km}$ horizontally and $60 \mathrm{~m}$ vertically) between 8.2 and $20 \mathrm{~km}$. The cloud cover is computed on an instantaneous basis for three atmospheric layers located below $3.2 \mathrm{~km}$, between 3.2 and $6.5 \mathrm{~km}$, and above $6.5 \mathrm{~km}$. Because of the long revisit times of the A-Train $(\sim 16 \mathrm{~d})$, the data are accumulated at seasonal timescales.

Three above-cloud AOD (ACAOD) products are used. The first is obtained from the POLDER-3/PARASOL instrument as described by Waquet et al. (2013) and Peers et al. (2015). Briefly, this is a two-step retrieval where the first step uses the polarization radiance measurements to retrieve the scattering AOD and the aerosol size distribution in a cloudy scene. In the second step, the spectral contrast and the magnitude of the total radiances measured in the visible and SWIR are used to retrieve the absorption AOD and cloud optical depth (COD) simultaneously. Therefore, the retrieval of the aerosol properties is done with minimal assumptions and with the cloud properties corrected for the overlying aerosol absorption.

Two MODIS-based products are also used. One, the Deep Blue ACAOD data set, was described initially by Sayer et al. (2016) and updated and evaluated against ORACLES field campaign data by Sayer et al. (2019). In brief, this algorithm performs a multispectral weighted least-squares fit of measured reflectance in four bands across the visible spectral region to simultaneously retrieve ACAOD and COD. Finally, the MOD06ACAERO products are also used, which take reflectance observations at six MODIS spectral channels to simultaneously retrieve ACAOD, COD and the cloud effective radius of the underlying marine boundary layer clouds (Meyer et al., 2015). The main conceptual difference between these two MODIS data sets is that the former was designed primarily to extend AOD coverage into cloudy scenes, while the latter was designed to address known regional bi- 
ases in cloud property retrievals resulting from the BBA signal. In addition to these above-cloud AOD data sets, two total-column AOD data products are used: MODIS Dark Target Collection and MISR (Kahn and Gaitley, 2015). While the above-cloud aerosol loading is most relevant to the SDE, these total column products are used for wider context.

\section{Evaluation}

\subsection{Surface radiation and temperature}

Shortwave surface radiation from RegCM and ALADIN (control runs) have been estimated using the PIRATA buoy observations at the station at $6^{\circ} \mathrm{S}, 8^{\circ} \mathrm{E}$. The SARAH-2 downwelling radiation data at the PIRATA buoy has been also included in the comparison. Results are provided in the Supplement (Fig. S1) indicating a relatively good agreement between ALADIN and SARAH-2, especially during the biomass-burning season. A more significant positive bias $\left(\sim 40 \mathrm{~W} \mathrm{~m}^{-2}\right)$ is found in ALADIN when compared to in situ PIRATA observations. This bias in ALADIN is due to the underestimation of the cloud fraction over SEA (Fig. 1). The results obtained for RegCM clearly indicate a better agreement with the PIRATA observations and a slight underestimation compared to SARAH-2. Figure S1 also highlights the large difference between the PIRATA and SARAH-2 data for the period studied. Foltz et al. (2013) indicate that aerosol deposition could affect the observed surface radiation. Concerning surface temperature, the comparison with CRU data reveals (Fig. S2) a positive bias of $\sim 1-2 \mathrm{~K}$, especially over central Africa in ALADIN for the CTL run. The bias in surface temperature is more significant $(\sim 2-4 \mathrm{~K})$ over the south of the Democratic Republic of Congo and Angola. RegCM simulation shows a similar bias magnitude range but different spatial patterns, ranging between $\sim-1$ and $-3 \mathrm{~K}$ for the equatorial sub-region to $+4 \mathrm{~K}$ for the coastal Namibian sub-region. Many factors can affect surface temperature bias such as cloudiness, precipitation or boundary layer scheme. The bias showed by these regional simulation is in the range of other RCM studies realized in the frame of CORDEX (Laprise et al., 2013).

\subsection{Cloud microphysical and macrophysical properties}

As the first indirect effect is not treated here, the analyses are focused mainly on LCF and LWP. The seasonal (JulyAugust-September, JAS) mean of LCF is shown in Fig. 1 for the two RCMs and the SEVIRI and CALIOP instruments. The analyzed period is 2004-2015. First, some important differences appear between the two satellites, especially over the Gulf of Guinea and south of $25^{\circ} \mathrm{S}$, where LCF is higher in CALIOP data. Compared to models, Fig. 1 indicates a significant underestimation in LCF by ALADIN during the JAS season over the main Sc region, mainly between $5-20^{\circ} \mathrm{S}$ and $12^{\circ} \mathrm{E}-15^{\circ} \mathrm{W}$. Over this zone, RegCM simulates larger LCF
( $\sim 90 \%$ ), which is in better agreement with SEVIRI and CALIOP. The regional extent of $\mathrm{Sc}$ is well reproduced by RCMs, with a decrease above $\sim 5^{\circ} \mathrm{S}$ in agreement with SEVIRI observations. Over this region, both RCMs are able to reproduce reasonably well the LCF derived from SEVIRI, especially the decrease along the Guinean coast, but an underestimation is noted compared to CALIOP. The extent of the Sc region to the south is also well captured by ALADIN and RegCM compared to SEVIRI but is largely underestimated compared to CALIOP, especially below $20^{\circ} \mathrm{S}$. The extent of Sc to the west is limited to $\sim 10^{\circ} \mathrm{W}$ by the two models, while satellite observations indicate high values up to $15^{\circ} \mathrm{W}$. More specifically, the small LCF observed by SEVIRI and CALIOP along the Namibian coast is overestimated more in RegCM compared to ALADIN. Finally, over the continent, Fig. 1 indicates that both models simulate LCF higher than $40 \%$ over the Gabon. In this specific region, the simulated LCF by RegCM is found to be very consistent with satellite SEVIRI observations, while in ALADIN it is more consistent with CALIOP data.

In Fig. 2a, the simulated interannual variations of the seasonal-mean (JAS) LCF are also compared to SEVIRI and CALIOP observations, as well as ERAI reanalyses, over the Sc representative geographical box $\left(10-20^{\circ} \mathrm{S}, 0-10^{\circ} \mathrm{E}\right) \mathrm{de}-$ fined by Klein and Hartmann (1993) over the Atlantic. As mentioned previously, ALADIN underestimates LCF with a mean value of $63 \%$ for the JAS season (Fig. 2a) compared to SEVIRI (77\%), ERAI (75\%) and CALIOP data (88\%). This lack of LCF in ALADIN is consistent with the cloud biases found in its global counterpart (ARPEGE-Climat, Roehrig et al., 2020). Brient et al. (2019) attributed these biases to issues with the prescribed subgrid-scale distributions of water and temperature in the cloud parameterization and with overestimated drying induced by the cloud-top entrainment parameterization. Concerning RegCM, the comparison indicates that the LCF is slightly overestimated during the JAS season compared to SEVIRI and ERAI, but a good agreement is obtained with CALIOP data. Since LCF does not give any indication of simulated cloud thickness which is important for radiative feedbacks, the simulated LWP is analyzed in Fig. 2b. For this variable, only ERAI and SEVIRI have been considered. The results generally indicate that the two models are able to simulate consistent values compared to the observations. For ALADIN, the mean value $\left(0.064 \mathrm{~kg} \mathrm{~m}^{-2}\right.$ for the CTL simulation) obtained for the 2000-2015 period generally falls within the spread of ERAI and SEVIRI LWP $\left(0.06-0.07 \mathrm{~kg} \mathrm{~m}^{-2}\right)$. Figure $2 \mathrm{~b}$ indicates that RegCM slightly overestimates LWP with a mean value of $0.08 \mathrm{~kg} \mathrm{~m}^{-2}$. These results indicate that even though the models exhibit some important bias in LCF, which is known to be a critical unresolved problem in the global modeling communities (Nam et al., 2012), the LWP is reasonably well simulated by both models. Nevertheless, the model differences and biases discussed above should be kept in mind for further analysis of 


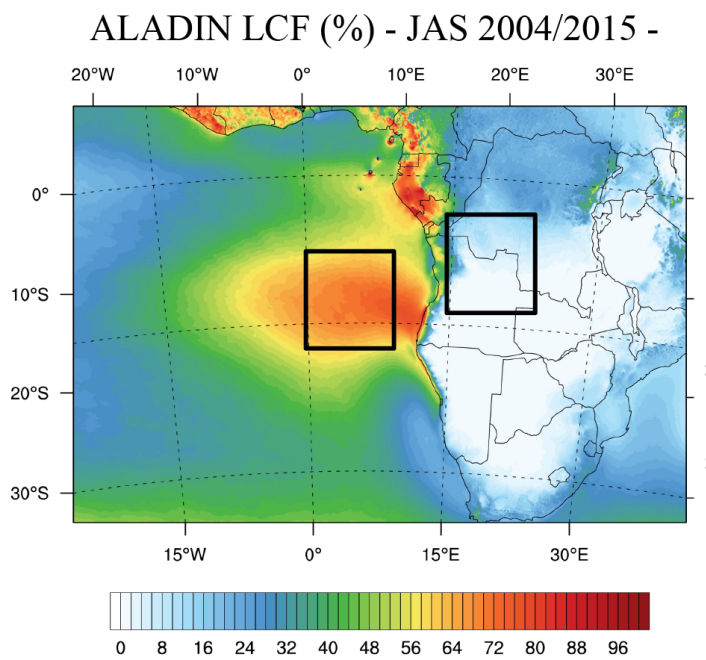

RegCM LCF (\%) - JAS 2004/2015 -

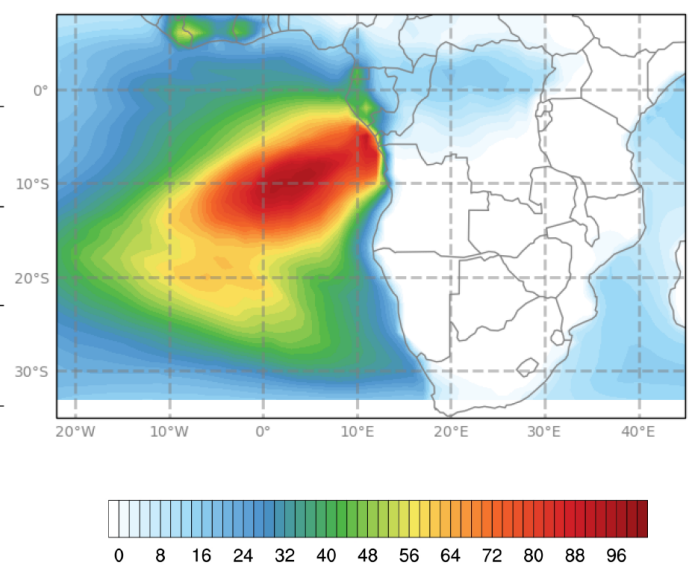

CALIOP LCF (\%) - JAS 2004/2015 -

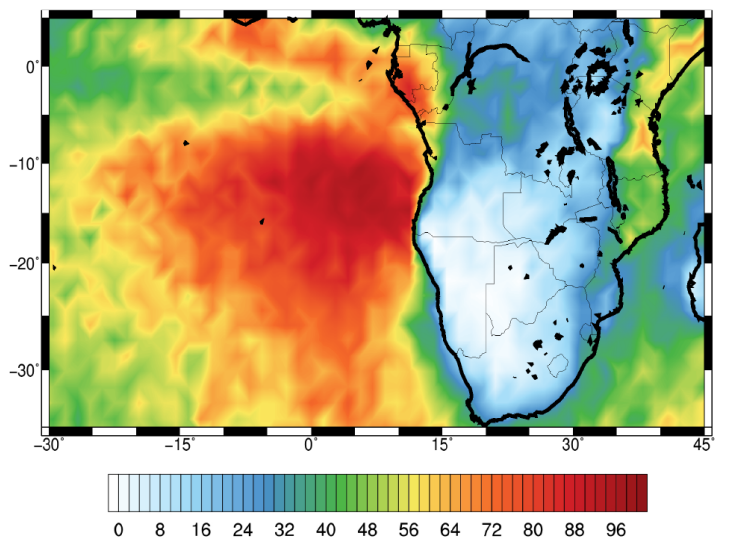

SEVIRI LCF (\%) - JAS 2004/2015 -

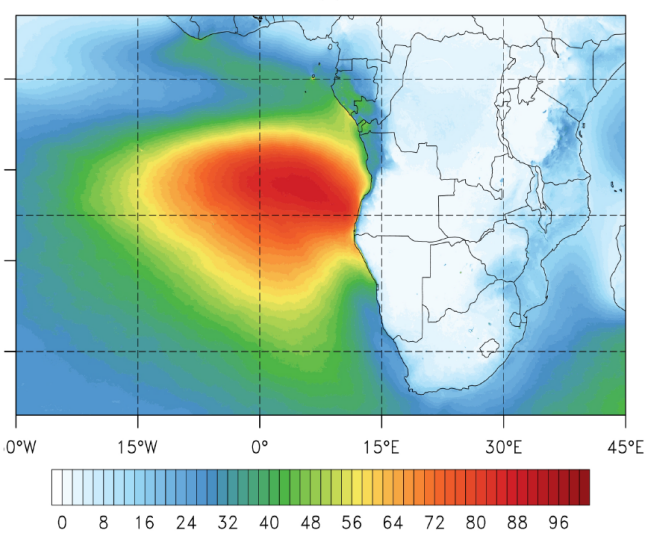

Figure 1. Seasonal (JAS) mean of the LCF (\%) simulated for the ALADIN (2004-2015) and RegCM (2004-2015) models (CTL runs) and retrieved by the SEVIRI and CALIOP (2004-2015) instrument. The two different boxes (Box_0 and Box_S are indicated). The Box_0 (10-20 $\left.\mathrm{S}, 0-10^{\circ} \mathrm{E}\right)$ has been defined by Klein and Hartmann (1993).

the DRE of smoke exerted at TOA, especially over the main $\mathrm{Sc}$ region $\left(10-20^{\circ} \mathrm{S}, 0-10^{\circ} \mathrm{E}\right)$.

\subsection{Aerosol optical properties}

\subsubsection{Total column AOD}

The simulated seasonal (JAS) mean AOD values (at $550 \mathrm{~nm}$ ) are reported in Fig. 3 (2008-2015 period), along with the CAMS-RA and MERRA-2 reanalyses, and the MODIS Dark Target (Aqua and Terra) and MISR satellite AOD products. Concerning the satellite data (MODIS-Terra, MODISAqua, MISR), comparisons indicate important differences, over both the ocean and the continent. In particular, large differences are found between MODIS and MISR AOD retrievals, with lower values associated with MISR at the regional scale. The latter is in a better agreement with the two RCMs, especially over the ocean. The difference obtained in this study between the two sensors are in line with the recent results obtained by Sogacheva et al. (2020) over SEA. For the current MISR standard product, this study indicates that AOD is systematically underestimated for AOD $>\sim 0.5$, largely due to treatment of the surface boundary condition at high AOD (Kahn et al., 2010). As mentioned by Mallet et al. (2019), some of the land-ocean contrast in the satellite data comes from different factors, such as the over-land and over-water algorithms, which are different and may present different biases. The second is that cloud fraction is also significantly higher over the water than over the land, meaning that typically more days of data contribute to the monthly mean over land than over water.

The magnitude of the simulated AOD is quite consistent among the two models over the ocean but diverges over the continent where AOD simulated by ALADIN is larger, especially over the eastern part of Congo. In this region, the 
(a)

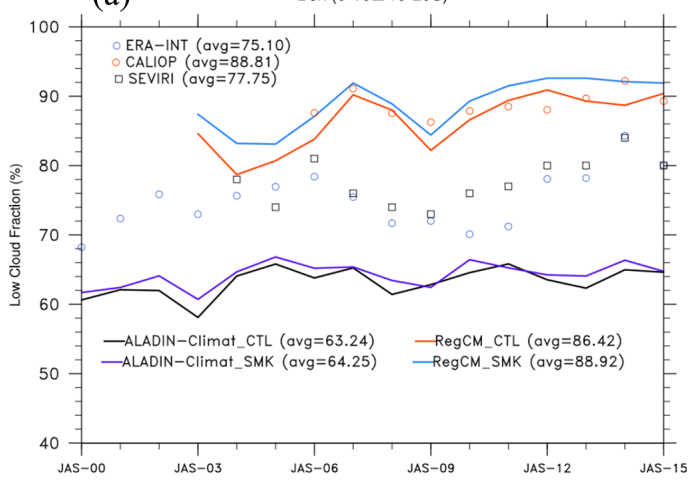

(b)

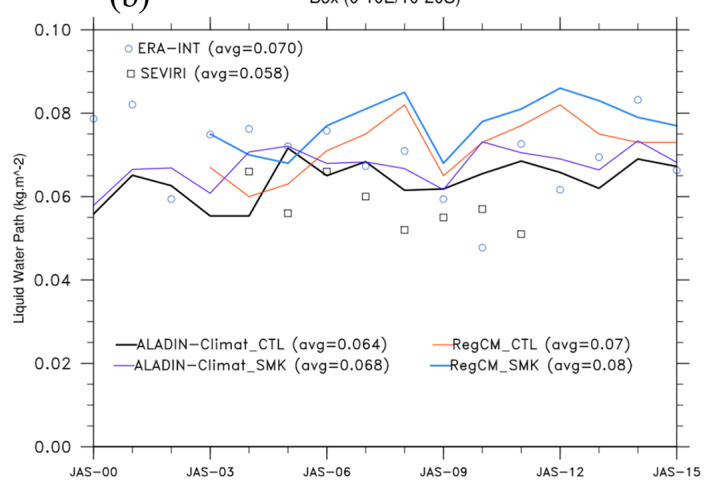

Figure 2. (a) Low-cloud fraction (\%) and (b) liquid water path $\left(\mathrm{kg} \mathrm{m}^{-2}\right)$ obtained by CALIOP, SEVIRI, ERA-Interim (grid-box mean) and the two regional models over the Box_0 (10-20 S/0-10 E) defined by Klein and Hartmann (1993). CTL and SMK simulations are shown for both models.

difference in AOD between the two models is $\sim 0.2-0.3$. Numerous reasons could explain these differences, including the temporal frequency of the emissions (monthly vs. daily) used to force the model, vertical and horizontal transport processes, optical properties (mass extinction efficiencies) such as the effect of relative humidity, and wet removal processes in connection with the location and amplitude of the precipitation. Another likely contributing factor is sampling incompleteness of the satellite products, particularly over the parts of the region with high cloud cover (e.g., Fig. 2 of Sayer et al., 2019). Over the ocean, the two regional models are in relatively good agreement, with AOD values of $\sim 0.6-0.7$ near the Angolan and Gabonese coast which decreases to $\sim 0.4$ 0.5 near $0^{\circ}$. Figure 3 also shows higher AOD north of the Equator in RegCM, possibly due to the fact that the simulation domain extends further north and accounts for Northern Hemisphere aerosol sources. In addition, RegCM and ALADIN are found to be consistent with the reanalysis data, especially with MERRA-2 AOD even if the AOD is weaker over eastern Congo, as is the case for RegCM. Larger differences are observed between RegCM and CAMS data for the same region, while a better agreement is found with ALADIN. The maxima of AOD is also well reproduced by ALADIN compared to CAMS. Finally, the comparisons indicate that RegCM and ALADIN-Climat underestimate AOD north of Gabon and Congo. Finally, it should be mentioned that some bias in AOD could be due to the simulated relative humidity in the free troposphere. As shown by Mallet et al. (2019), a negative bias in the BBA extinction profiles is detected in ALADIN simulations in its non-nudged version.

In addition to the regional distribution of total AOD, the seasonal cycle has also been analyzed in Fig. 4. The different AOD estimates have been averaged over the box at $5-15^{\circ} \mathrm{S}, 15-25^{\circ} \mathrm{E}$ (referred to as box_S) located over the main biomass-burning sources of central Africa. This figure includes monthly-averaged AOD estimated by RegCM (2003-2015), ALADIN (2000-2015), CAMS-
RA (2008-2015), MERRA-2 (2008-2015), MACv2 (2005) and MODIS (2002-2017). The simulated AOD from ALADIN has been reported for the three different SSA used in the simulations and shows very similar results. This figure indicates that both models are able to correctly simulate the order of magnitude of reanalyses, climatology and satellite AOD with the maxima between 0.4 and 0.7 during the biomass-burning season, where $\mathrm{RegCM}$ is particularly close to MERRA-2 AOD reanalyses. Yearly-averaged AOD values indicate that both model estimates, namely ALADIN (0.27) and $\mathrm{RegCM}(0.25)$, are within the range of values reported by the different data set $(0.20-0.32)$. ALADIN is found to be consistent with CAMS-RA data in terms of AOD seasonal amplitude, even if a shift is apparent with stronger values at the beginning of the fire season in particular. This difference could be due to precipitation biases in the ALADIN model or other aerosols advected at the boundary of the domain. Finally, the comparisons over the smoke source region point out a slight underestimation $(\sim 0.05)$ of AOD for the November to March period by both models compared to CAMS and MODIS, which could be due to different reasons such as the long-range transport (especially for ALADIN, which does not include chemical forcing at the boundaries), emissions or some bias in the precipitation (impact on the wet deposition). Despite these differences, the seasonal cycle of the total AOD is relatively well reproduced by both models. The temporal correlation, estimated with MODIS and MISR data, is higher $(\sim 0.95)$ in $\operatorname{RegCM}$ than in ALADIN $(\sim 0.80)$.

\subsubsection{Total above-cloud AOD}

Figure 5 displays the averaged values of ACAOD $(550 \mathrm{~nm})$ for the JAS period simulated by the two RCMs (SMK simulations), PARASOL, MODIS-DB Aqua, MODISACAERO Aqua and Terra. Due to the implication for semi-direct effects, this parameter is evaluated over the ocean box at $10-20^{\circ} \mathrm{S}, 0-10^{\circ} \mathrm{E}$, where the Sc deck is present. The sim- 
ALADIN AOD (550 nm) JAS - 2008/2015
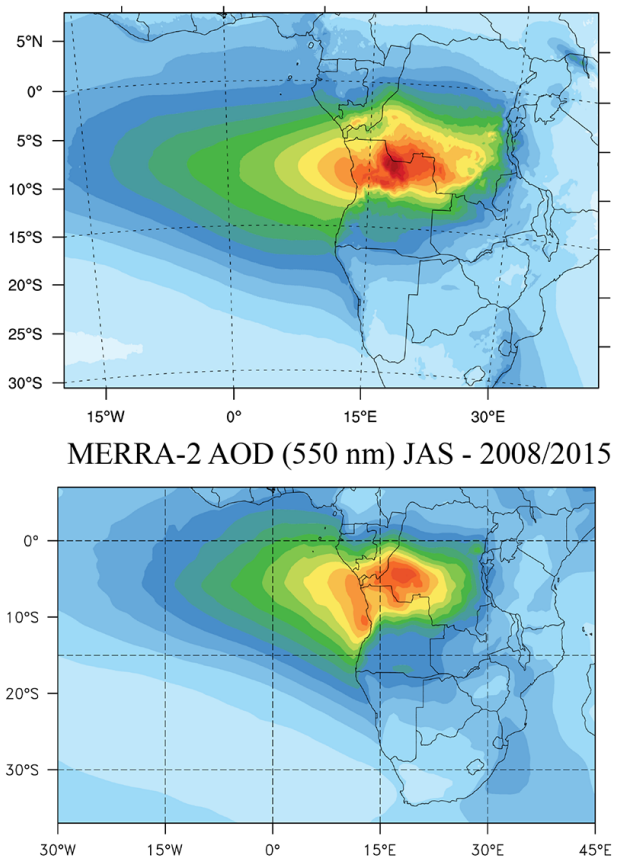

RegCM AOD (550 nm) JAS - 2008/2015

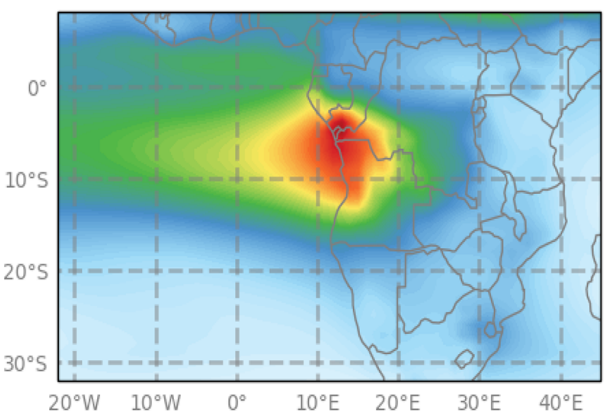

CAMS-RA AOD (550 nm) JAS - 2008/2015

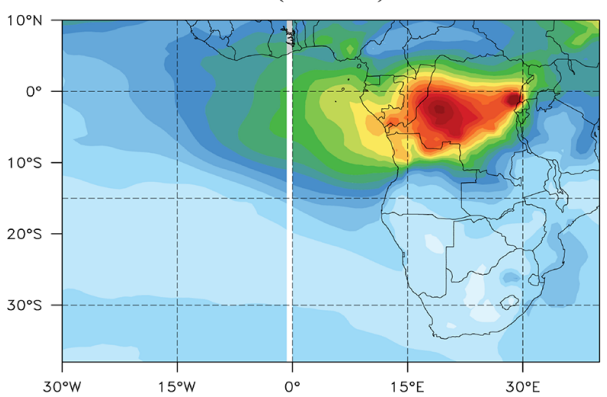

MODIS-AQUA AOD (550 nm) JAS - 2008/2015

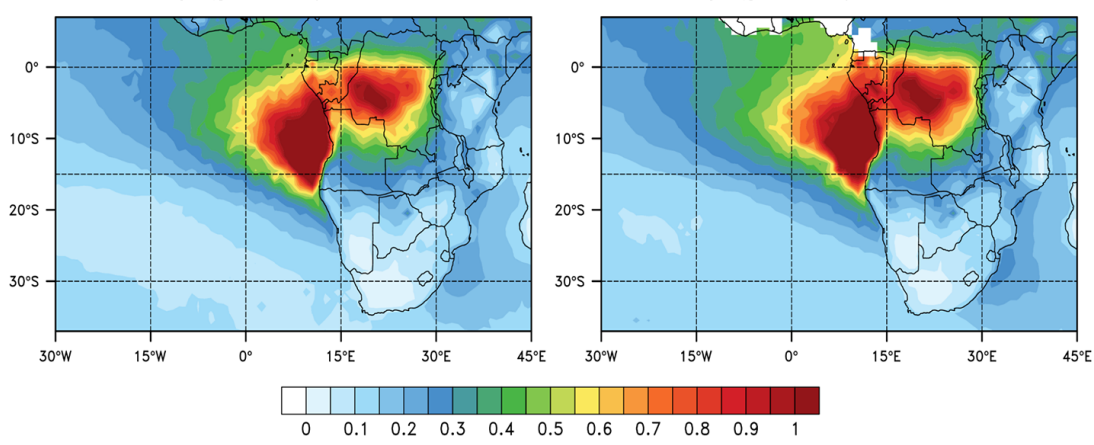

MODIS-TERRA AOD $(550 \mathrm{~nm})$ JAS - 2008/2015

MISR AOD $(550 \mathrm{~nm})$ JAS - 2008/2015

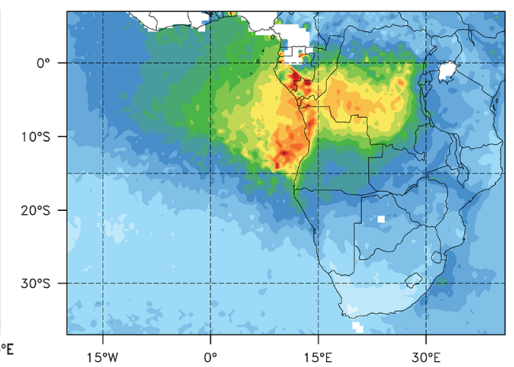

Figure 3. Total aerosol optical depth (AOD) estimated at $550 \mathrm{~nm}$ by the two RCMs (ALADIN and RegCM for the CTL runs), two reanalyses (CAMS-RA and MERRA-2) and two satellite products (standard MODIS and MISR AOD). The different period of observations and simulations are reported.

ulated ACAOD is underestimated $(\sim-0.1$ to -0.2$)$ by the two RCMs compared to the MODIS-DB Aqua, MODISACAERO Aqua and Terra and PARASOL data, with averaged-values (for the whole period) of $0.18,0.22,0.31$, $0.31,0.30$ and 0.36 for ALADIN, RegCM, MODIS-DB, MODISACAERO (Aqua and Terra) and PARASOL, respectively. As both models have been shown to correctly reproduce total AOD near the biomass-burning sources (Sect. 3.3.1), the differences in ACAOD, especially in 20082009 , could be due to differences in the altitude of transport of BBAs and cloud top (generally lower in RegCM) in the models, linked to boundary layer dynamics and convection (possible smoke plume intrusion into the marine boundary layer), scavenging, and possibly an underestimation of humidity contained within the smoke plume which can affect optical properties as shown recently by Mallet al. (2019). Figure S3 indicates the BBA extinction (at $550 \mathrm{~nm}$ ) and clearly shows an efficient transport of BBA plumes over the ocean in accordance with results obtained over SEA by Das et al. (2017). Extinction maxima are clearly localized between 1 and $4 \mathrm{~km}$ in both models but the base of the smoke plume is lower in RegCM. This may explain differences in the ACAOD between the two regional models as well as the altitude of the cloud top. The ORACLES model-observation intercomparison analysis also points to a lower extinction in the different models within the BBA layer (Shinozuka et al., 2020). While further analysis is needed, it is outside the scope of this work. However, the simulated negative bias in ACAOD is relevant to the DRE and SDE of smoke aerosols over SEA and is further discussed in following sections. 


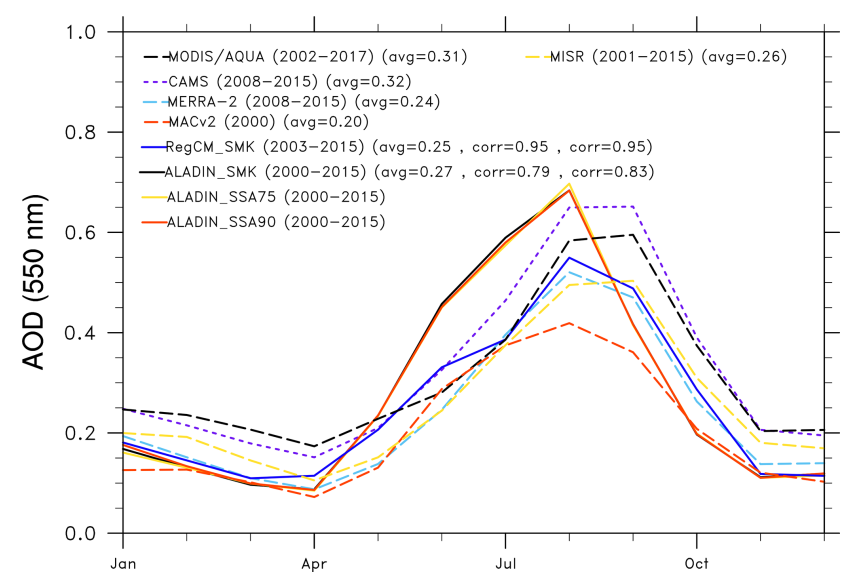

Figure 4. Monthly-mean total AOD $(550 \mathrm{~nm})$ averaged over the Box_S $\left(5-15^{\circ} \mathrm{S}, 15-25^{\circ} \mathrm{E}\right)$ for the MODIS/Aqua (standard AOD) and MISR instruments, CAMS-RA and MERRA-2 reanalyses, and ALADIN and RegCM models. For ALADIN-Climat, the CTL, SMK_75 and SMK_90 simulations are reported. The different periods of the observations and simulations are indicated. The AOD temporal correlations for each model, estimated with MODIS and MISR data, are also reported.

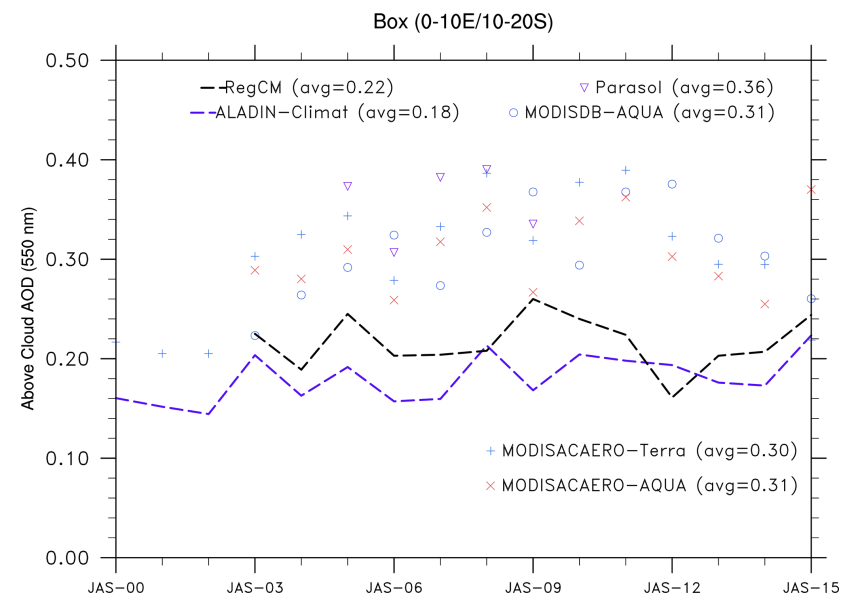

Figure 5. Seasonal (JAS) mean of the total ACAOD $(550 \mathrm{~nm})$ averaged over the box_O. RegCM (2003-2015) and ALADIN (20002015) SMK simulations and PARASOL (2005-2009), MODIS Deep Blue Aqua (2003-2015), MODISACAERO Terra (20002015) and MODISACAERO Aqua (2003-2015) satellite observations are reported.

Nevertheless, the magnitude of the simulated ACAOD is consistent with other satellite-based studies. For example, during the JJA period and over the SEA, Kacenelenbogen et al. (2019) reported a seasonally averaged ACAOD of 0.25 , close to the ALADIN and RegCM estimates. Based on monthly-mean time series of ACAOD over SEA using different instruments (SeaWiFS, MODIS Terra and Aqua, VIIRS), Sayer et al. (2019) found typical values of $\sim 0.3$ during the biomass-burning season for the period 2000 to 2015 . Es-

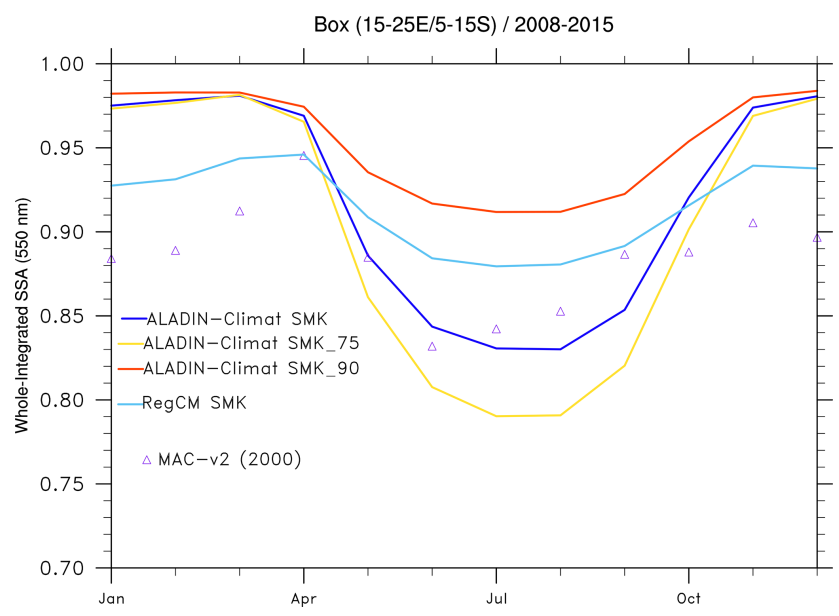

Figure 6. Monthly-mean SSA $(550 \mathrm{~nm})$ averaged over the Box_S (15-25 E $\left./ 5-15^{\circ} \mathrm{S}\right)$ for the ALADIN (2000-2015), and RegCM (2003-2015) models and the MACv2 climatology. The CTL, SMK_75 and SMK_90 ALADIN simulations are shown.

sentially the same retrieval algorithm was applied to the four sensors.

\subsubsection{Aerosol absorbing properties}

As mentioned in the introduction, DRE and SDE of BBAs are highly sensitive to absorbing properties of smoke. In order to evaluate these properties, we have compared (Fig. 6) the monthly-mean SSA (for all aerosols over the whole atmospheric column and at $550 \mathrm{~nm}$ ) obtained by RegCM (20032015) and ALADIN (2000-2015) with the recent MACv2 (year 2005) climatology over the box_S $\left(5-15^{\circ} \mathrm{S}, 15-25^{\circ} \mathrm{E}\right)$. We recall that monthly sun-sky photometry statistics (from AERONET; Dubovik and King, 2000) were used as part of the MACv2 climatology (Kinne, 2019). The comparison indicates that the ALADIN SMK simulation is able to capture the seasonal cycle of SSA, especially between April and October. This simulation produces a SSA of $\sim 0.85$ during JJA, which is consistent with the MAC-v2 data. A negative bias is present in September in which ALADIN underestimates SSA compared to MACv2. As expected by their construction, the two additional ALADIN simulations indicate lower (SMK_75) and higher (SMK_90) SSA compared to MACv2 data during the biomass-burning season. RegCM is also able to capture the seasonal variability of SSA during the June to October season, in spite of an overestimate of $\sim 0.03-0.04$.

Interestingly, Fig. 6 also reveals that the ALADIN SSA is largely overestimated compared to MACv2 from November to March. This could be due to the fact that the ALADIN simulations do not take into account transport through the boundary of the domain. The lack of possible advection of BBAs from western Africa and/or mineral dust within the defined ALADIN domain could partly explain this overesti- 
Surface Direct Radiative Effect $\left(\mathrm{W} \mathrm{m}^{-2}\right)$
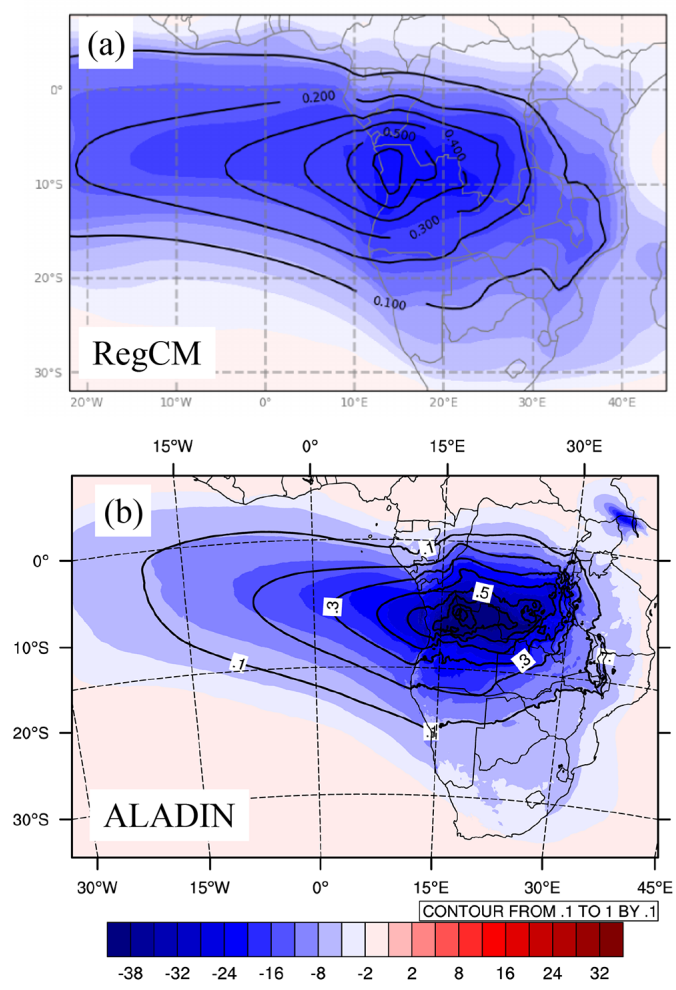

Surface Temperature changes $(\mathrm{K})$
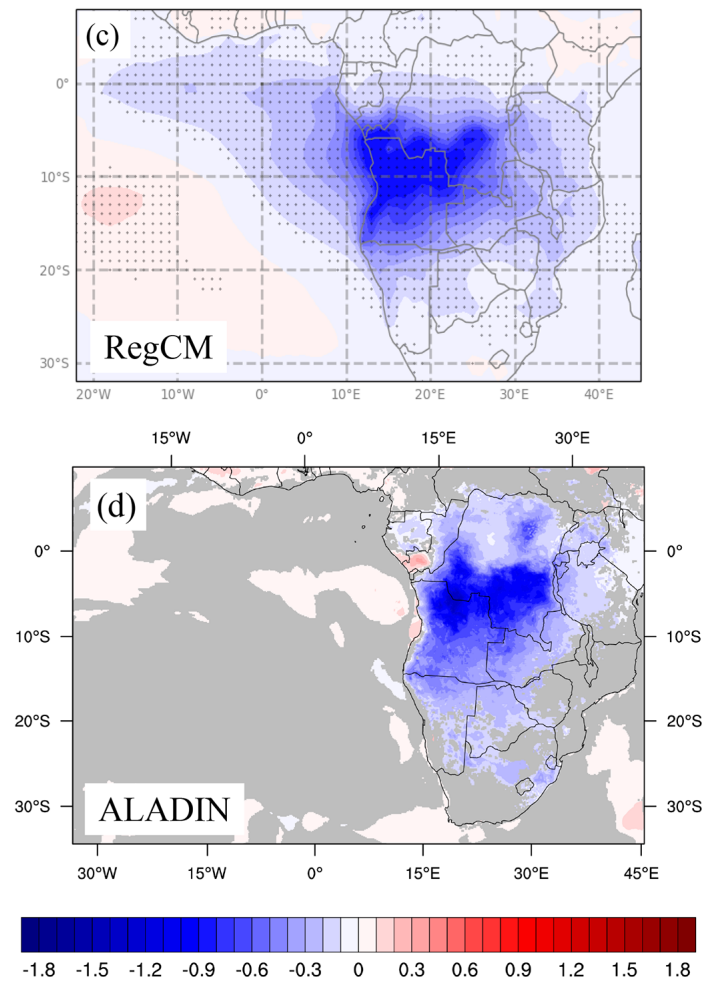

Figure 7. Seasonal-mean (JAS) DRE ( $\mathrm{W} \mathrm{m}^{-2}$ ) exerted by BBAs at the surface in the shortwave (all-sky conditions) for the ALADIN (b) and RegCM (a) models. The AOD values of BBAs are indicated by the black lines. Seasonal-mean (JAS) changes in the surface temperature due to the BBA DRE for the ALADIN (d) and RegCM (c). For the surface temperature map, the grey (not dashed) areas are not statistically significant at the 0.05 level for ALADIN (RegCM).

mation. This positive bias is partially reduced in the $\mathrm{RegCM}$ simulations, which are performed on a larger domain. Finally, it should be noted that this range of simulated SSA by the two models is consistent with the SSA climatology reported by Eck et al. (2013) of $\sim 0.82-0.87(550 \mathrm{~nm})$ during the biomass-burning season for the 1997 to 2005 period at the Mongu AERONET station in Zambia.

\section{Direct (SW) radiative effect of smoke aerosols}

\subsection{Impact at the surface}

Figure 7a and $\mathrm{b}$ display the JAS (SW) all-sky DRE of BBAs exerted at the surface over southern Africa for ALADIN (2000-2015) and RegCM (2003-2015). The results clearly indicate a significant decrease in solar radiation at the continental and oceanic surfaces due to BBAs and its cloud response. In accordance with the simulated AOD (contour lines), in both RCMs the DRE of smoke particles at the surface is larger over the continent and decreases as the BBA plume dilutes during transport over the SEA. In general, the seasonally averaged DRE is -30 to $-40 \mathrm{~W} \mathrm{~m}^{-2}$ near the biomass-burning emission regions and reaches val- ues of about -10 to $-20 \mathrm{~W} \mathrm{~m}^{-2}$ over the ocean in ALADIN and RegCM. Such estimates are consistent with those reported by Sakaeda et al. (2011) and Tummon et al. (2010) in this region. In addition, the simulated DRE over central Africa is consistent with those reported recently by Allen et al. (2019) with a yearly-mean DRE of $\sim-20 \mathrm{~W} \mathrm{~m}^{-2}$. As noted for AOD, the dimming effect of smoke in RegCM is higher over the Gulf of Guinea and in the SEA outflow than estimated in ALADIN. In addition and even if a good agreement is generally noted with the different studies, the overestimation of the LCF by RegCM over the SEA (Sect. 3.2), in particular with respect to SEVIRI observations, may lead to an overestimation of the DRE by BBAs in this model. The opposite effect is assumed in the results of ALADIN, which generally underestimates LCF.

The impact of DRE on surface temperature is analyzed in Fig. 7c and d. Over the continent, a significant cooling of up to -1.0 to $-2.0 \mathrm{~K}$ is calculated by both models. Such decreases in the continental surface temperature have already been documented in the literature by Sakaeda et al. (2011), Tummon et al. (2010) and more recently by Mallet et al. (2019), all showing similar changes. Surface cooling associated with the lower troposphere heating due 
(a) TOA (SW) Direct Radiative Forcing $\left(W \mathrm{~m}^{-2}\right)$ - JAS 2000/2015 -

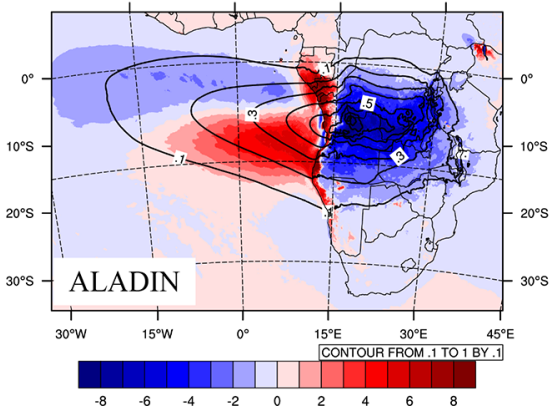

(b) TOA (SW) Direct Radiative Forcing $\left(\mathrm{W} \mathbf{m}^{2}\right)$ - JAS 2003/2015 -

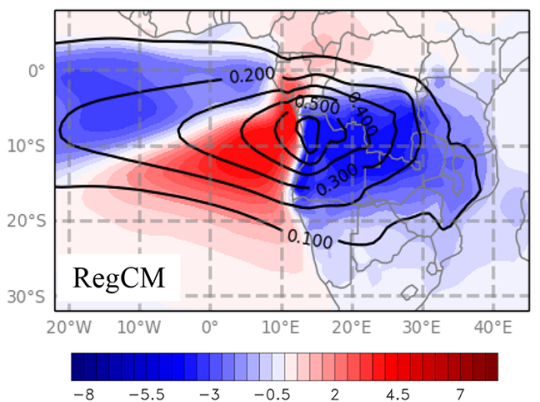

(c) TOA (SW) Direct Radiative Forcing $\left(\mathrm{W} \mathrm{m}^{-2}\right)$ - JAS 2005 -

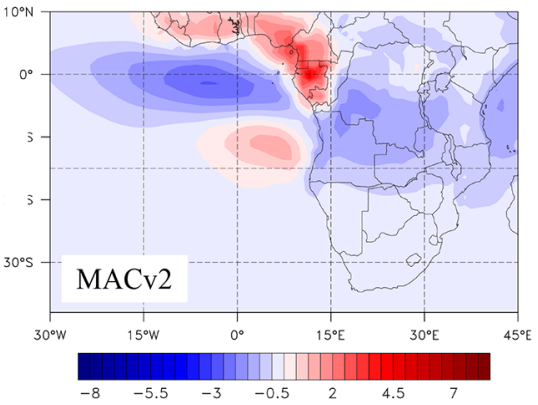

Figure 8. Seasonal-mean (JAS) BBA DRE $\left(\mathrm{W} \mathrm{m}^{-2}\right.$ ) exerted at TOA in the shortwave (all-sky conditions) for ALADIN (a, period 20002015), RegCM (b, period 2003-2015) and the MACv2 climatology (c, year 2005). The ISCCP-based cloud cover for high ( $<440 \mathrm{hPa}$ ), middle $(440-680 \mathrm{hPa})$ and low $(>680 \mathrm{hPa})$ altitudes are used for the MACv2 radiative transfer calculations. The AOD of BBAs are indicated by the black lines.

to BBAs has been shown to limit the development of the continental boundary layer (Tummon et al., 2010; Mallet et al., 2019). Figure 7c and d also indicate higher cooling over southern Africa in ALADIN compared to RegCM in spite of relatively similar surface radiative forcing (Fig. 7a and b), which could be due to the advection of colder air in ALADIN in the SMK simulation (see Sect. 5.2). RegCM uses a slab ocean model in which the impact of BBAs on SST can be evaluated (Solmon et al., 2015). Figure 7c clearly indicates that the sea-surface solar radiation dimming by BBAs impacts simulated SST which is regionally decreased over a large part of SEA (reaching $5^{\circ} \mathrm{W}$ ). In this simulation, the SST cooling is not only due to the BBA direct effect, but also from a positive feedback of Sc clouds via semi-direct effects (see Sect. 5). We can also note an increase in SST in RegCM around $20^{\circ} \mathrm{W}$, which is due to a decrease in the LCF (see Fig. 12).

Figure 7c indicates that the largest SST changes, around -1 to $-1.5 \mathrm{~K}$, are produced close to the Angolan and Gabonese coasts and co-located with AOD maximum in the RegCM simulation. However, the cooling signal is produced over a large part of SEA, from $15^{\circ} \mathrm{S}$ to $0^{\circ}$ and from $8^{\circ} \mathrm{E}$ to $5^{\circ} \mathrm{W}$, as the result of cloud feedbacks and dynamical adjustments. Over this large oceanic region, the decrease in SST varies between -0.5 and $-0.2 \mathrm{~K}$ which is consistent with results obtained by Sakaeda et al. (2011), who also used a slab ocean model. The magnitude of the SST cooling is slightly lower in our study, probably due to differences in low-cloud feedbacks. As mentioned earlier, the overestimation of the LCF by RegCM over most of the SEA compared to SEVIRI may also lead to an overestimation of the impact of BBAs on SST.

\subsection{Impact at the top of the atmosphere}

As mentioned earlier, the sign of the overall BBA TOA radiative forcing over the SEA region is quite uncertain in GCM simulations (Stier et al., 2013). Figure 8 represents the JAS DRE simulated by ALADIN (2000-2015), RegCM (20032015) and MACv2 (2005). The results show a large negative DRE $\left(\sim-10 \mathrm{~W} \mathrm{~m}^{-2}\right)$ at TOA over the continent, with maxima over Angola, consistent in the two RCMs. These results are in line with previous studies (Tummon et al., 2010; Mallet et al., 2019; Sakaeda et al., 2011) that report significant negative TOA DRE over southern Africa during the BBA season. This signal over the continent is also consistent with that of the MACv2 climatology (Kinne, 2019), even if the magnitude is less than in the RegCM and ALADIN simulations.

Simulated TOA DRE shows a dipole pattern over the SEA with positive DRE south of $5^{\circ} \mathrm{S}$ and negative DRE further north. This pattern is very similar between the two RCMs and in good agreement with the MACv2 data (Fig. 8). This strong gradient is determined by the large decrease in lowcloud fraction with latitude as one moves northwards from $5^{\circ} \mathrm{S}$ (as shown in Fig. 1), which strongly modifies the planetary albedo beneath BBA layers. As transported BBA plumes are not exactly co-located with Sc clouds (as shown by the AOD lines in Fig. 8), absorbing BBAs located south (north) of $5^{\circ} \mathrm{S}$ induce large positive (negative) DRE at TOA. In spite of the non-negligible LCF simulated over the Gulf of Guinea, the simulated cloud optical depth does not reach the critical value which would allow the BBAs to switch to a positive DRE at TOA. These results clearly highlight a complex regional pattern, different than that reported in the AeroCom exercise (Stier et al., 2013), which shows a more uniform (either positive or negative) DRE over SEA simulated by the different GCMs, except for CAM3, OsloCTM2 and HadGEM2-ES. More recently, Zou et al. (2020) indicate an averaged DRE (at TOA) over SEA under present-day conditions to be very consistent (see Fig. 3a of Zou et al., 2020) with the results obtained by ALADIN-Climat and RegCM.

Over SEA, simulated JAS DRE at TOA reaches a maximum of $\sim+5 \mathrm{~W} \mathrm{~m}^{-2}$ for both ALADIN-Climat and 
RegCM. This is consistent with recent estimates proposed by Kacenelenbogen et al. (2019), who reported (using a combination of A-Train satellite sensors) seasonal-mean values of $\sim+2.5-3 \mathrm{~W} \mathrm{~m}^{-2}$ for JJA and SON over SEA, including part of the Gulf of Guinea. However, the spatial extent of the positive DRE is larger in RegCM over SEA due to a larger cloud cover and thickness as well as a larger ACAOD compared to ALADIN. Differences appear notably over the Namibian coast, where the sign of the forcing is opposite between the two models, which is directly associated with the large and overestimated LCF simulated by RegCM over this region. As expected, RegCM simulates larger negative DRE at TOA over the Gulf of Guinea due to larger AOD over this specific region. In continental regions, Fig. 8 reveals a larger positive forcing in ALADIN over Gabon, which is certainly due to the larger LCF (see Fig. 1). We argue that this positive DRE is likely to be realistic due to the co-location of BBAs and persistent low-level clouds over the Gabon during JAS (Philippon et al., 2019).

In spite of some regional differences in the amplitude, the two model simulations clearly highlight a remarkable gradient in the DRE of BBAs. The approach of using two different independent RCMs reinforces the robustness of this original result. In addition, and although the amplitude of the DRE differs, this gradient over SEA is also clearly observed in MACv2, indicating maxima of $\sim+2-3 \mathrm{~W} \mathrm{~m}^{-2}$ over SEA and negative values $\left(-2\right.$ to $-3 \mathrm{~W} \mathrm{~m}^{-2}$ ) over the Gulf of Guinea, as shown in Fig. 8. As smoke SSA is found to be similar between the two RCMs and the MACv2 climatology (see Fig. 6), the observed differences in the magnitude of DRE over SEA could be due to variances in LCF as well as ACAOD. It should also be noted that the positive DRE simulated by ALADIN and RegCM over Gabon is detected in the reanalysis data as well. As mentioned earlier and although these results appear robust compared to recent reanalyses and literature in terms of amplitude, these DRE estimates at TOA remain marred by the problem of quantifying the LCF over this region (see Sect. 3.2), which is inherent in climate models.

\section{Semi-direct radiative effect}

\subsection{Impact on SW heating rate and air temperature}

The SDE, which represents the modifications of the cloud properties and atmospheric dynamics due to absorption of SW radiation by BBAs, has been estimated based on twin simulations, one including the impact of BBAs (SMK) and the other one for which BBA emissions are set to 0 (CTL; see Sect. 2.1.4). The SW radiative heating due to BBA absorption and potential feedbacks is shown in Fig. 9, which displays longitude-height cross sections at two latitudes (6 and $12^{\circ} \mathrm{S}$ ) averaged over JAS (2000-2015 for ALADIN and 2003-2015 for RegCM). The cross sections show the differ- ences between the SMK and CTL simulations. The results suggest that SW heating due to smoke is between +0.5 and $+1.5 \mathrm{~K}$ by day, with higher values at $6^{\circ} \mathrm{S}$ compared to $12^{\circ} \mathrm{S}$. The maximum of heating is located near the biomass-burning sources and decreases during the transport over the SEA to reach values $\sim+0.5 \mathrm{~K}$ by day at $\sim 10^{\circ} \mathrm{W}$ in both models. For the two RCMs, aerosol-induced solar heating occurs mostly between the surface and $5 \mathrm{~km}$ above the surface over the continent, and between 1 and $4 \mathrm{~km}$ over SEA in agreement with the vertical profiles of extinction (at $550 \mathrm{~nm}$; see Fig. S3). Figure 9 shows that most of the additional SW heating occurs mainly above $1 \mathrm{~km}$. The RegCM aerosol heating is larger than ALADIN at both latitudes, despite the fact that RegCM SSA is higher (less absorbing BBAs) in RegCM (see Fig. 6). This difference observed at 6 and $12^{\circ} \mathrm{S}$ could be due to the fact that there are more low clouds in the RegCM simulation that reinforce solar absorption within the smoke plumes. Over the continent and at both latitudes, higher solar heating in RegCM is linked to higher AODs over the source regions, especially near the coast as shown in Fig. 3. This can compensate the lesser absorbing efficiency of BBAs in RegCM compared to ALADIN. In addition, Fig. 9 shows a significant heating rate increase within the Sc clouds layer for the RegCM simulation. Further discussions on this issue are detailed in Sect. 5.3.

The simulated SW heating rates are within the range of values reported by different studies such as Tummon et al. (2010), Gordon et al. (2018), Adebiyi et al. (2015) and Wilcox (2010). These studies have indicated additional SW heating due to smoke of 1.00 (JJAS period), +0.34 ( $5 \mathrm{~d}$ of simulations), +1.20 (for fine AOD $>0.2$ ) and $+1.50 \mathrm{~K} \mathrm{~d}^{-1}$, respectively. In addition, Keil and Haywood (2003) estimated a SW heating rate of $1.80 \mathrm{~K} \mathrm{~d}^{-1}$ near the coast using a radiative transfer model and observations during SAFARI-2000.

Changes in the 3D air temperature (SMK minus CTL simulations) field due to BBAs are shown in Fig. 10 for the same latitudes as previously used for SW heating. For the two transects, a generally good agreement is found between the two RCMs. Over the continent in both models, smoke particles are responsible for a significant decrease in air temperature between the surface and $\sim 3-4 \mathrm{~km}$ height, with a higher vertical extent of cooling in ALADIN. The cooling at the surface is also more pronounced in ALADIN-Climat $(\sim-1 \mathrm{~K})$ compared to RegCM ( $\sim-0.5 \mathrm{~K})$. In both models above the continent, the simulated cooling between the surface and 3$4 \mathrm{~km}$ height is accompanied by a general heating of the midtroposphere (between 4 and $6 \mathrm{~km}$ ). As noted for the smoke cooling effect, the induced heating is more significant in the ALADIN simulation at these altitudes, which can be due to a number of factors, including the response of convection and dynamics to the aerosol perturbation. A detailed analysis of the change in the energy budget over the continental area is beyond the scope of the present study but is planned in the future. 

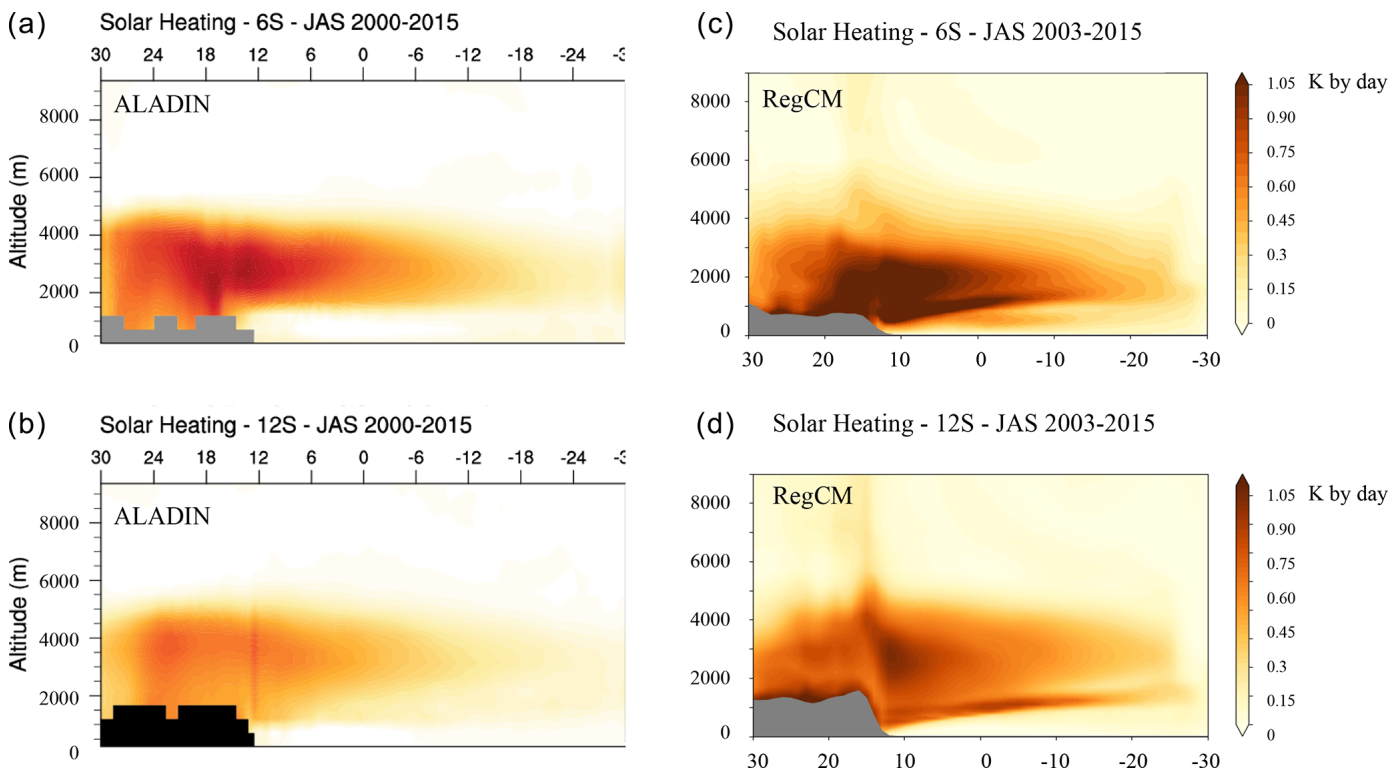

Figure 9. Seasonal-mean (JAS) changes (SMK minus CTL simulations) in the vertical profiles of SW heating rates (K by day) due to BBAs at two latitudes (6 and $12^{\circ} \mathrm{S}$ ), for the ALADIN (a, b, period 2000-2015) and RegCM (c, d, period 2003-2015) models.

(a)

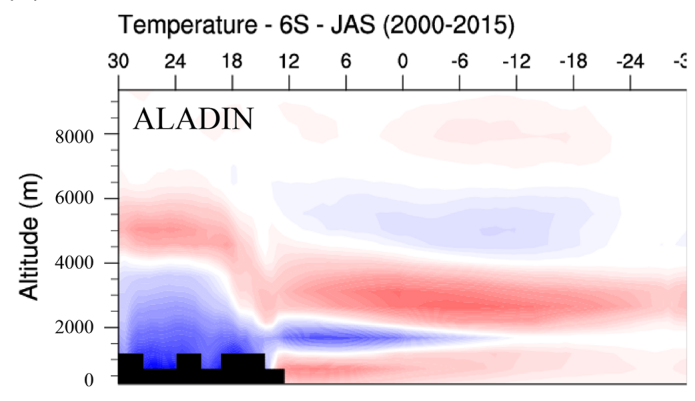

(b)

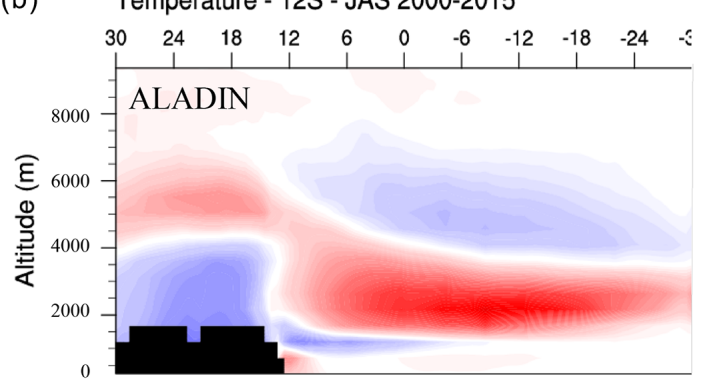

(c)

Temperature - 6S - JAS (2003-2015)

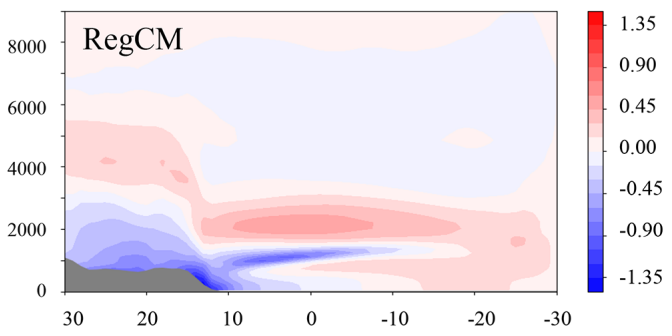

(d) Temperature - 12S - JAS (2003-2015)

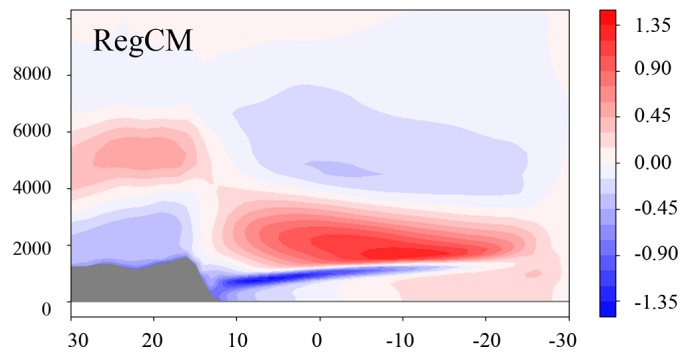

Figure 10. Seasonal-mean (JAS) changes (SMK minus CTL simulations) in the vertical profiles of air temperature due to BBAs at two latitudes (6 and $\left.12^{\circ} \mathrm{S}\right)$, for the ALADIN (a, b, period 2000-2015) and RegCM (c, d, period 2003-2015) models.

More interestingly, Fig. 10 clearly highlights differences in the models' response to air temperature near the surface close to the continent-ocean transition. For the two transects, the simulations differ where RegCM indicates a cooling (of $\sim 0.5-1 \mathrm{~K})$ near the surface, which is not simulated by AL-
ADIN. As mentioned previously, this difference is certainly due to the ocean-atmosphere coupling in RegCM that takes into account, in particular, the double impact of the BBA seasurface forcing as well as the increase in liquid water content of Sc (Sect. 5.3) on SST. This explains the difference in the 
air temperature changes obtained between RegCM and ALADIN close to the continent-ocean transition zone.

Over the Atlantic Ocean (Fig. 10), the simulated air temperature response is more complex. Air temperature generally increases by $0.5-1 \mathrm{~K}$ between 2 and $4 \mathrm{~km}$, where the core of smoke plumes are transported. At $6^{\circ} \mathrm{S}$, changes in the air temperature are found in ALADIN compared to RegCM, contrary to what is observed for the heating rate (Fig. 9). ALADIN simulates an increase in air temperature (between 2 and $4 \mathrm{~km})$ of $\sim 0.5-0.8 \mathrm{~K}$, larger than $\operatorname{RegCM}(\sim 0.2-$ $0.5 \mathrm{~K})$. In addition, Fig. 10 shows that the impact of smoke aerosols on air temperature is larger at $12^{\circ} \mathrm{S}$ than $6^{\circ} \mathrm{S}$, while the effect is opposite for the SW heating. Air temperature anomaly is not only determined by aerosol SW radiative heating but also results from additional feedbacks including lower tropospheric dynamics and cloud adjustment modifying the energy budget. As an example, over the continent the increase in air temperature between 5 and $7 \mathrm{~km}$ (at both latitudes) above the surface could be due to increase in the vertical ascent (see Fig. 12) of (hot) air masses. A specific study investigating changes in all the terms of the air temperature tendency would allow the different impacts to be quantified. The 2 to $4 \mathrm{~km}$ temperature changes obtained in this study are in a good agreement with values published by Sakaeda et al. (2011) (+0.5 K), Allen and Sherwood (2010) (+0.5$1 \mathrm{~K}$ at $700 \mathrm{hPa}$ and for the JJA period) and more recently by Gordon et al. (2018) (+0.4 K).

Under the smoke plume, RegCM and ALADIN both show a similar temperature response in a very tight layer, located between 1 and $2 \mathrm{~km}$, which is cooled by $\sim-0.5$ to $1 \mathrm{~K}$ (up to about $\left.10^{\circ} \mathrm{W}\right)$. This cooling could result from the additional scattering of solar radiation by the smoke plume located above but is likely to also be driven by additional LW cooling at the top of cloud layer due to the increase in Sc water content as a results of SDE (see Fig. S4). Finally, temperature changes in the marine boundary layer (MBL, surface to $\sim 1 \mathrm{~km}$ ) are quite different between the two RCMs, especially at $6^{\circ} \mathrm{S}$. The MBL is homogeneously heated by $\sim+0.5 \mathrm{~K}$ in ALADIN whereas RegCM exhibits a cooling, especially near the coast. As mentioned previously, this is linked to the slab ocean parameterization and SST cooling propagating to the MBL via turbulence in the case of RegCM. For ALADIN, heating of the MBL could be due to the LW trapping due to the increase in LWP and LCF at $6^{\circ} \mathrm{S}$ notably.

\subsection{Impact on the sea-level surface pressure and circulation}

For the first time to our knowledge, we have investigated in this work the SDE of BBAs on the lower tropospheric dynamics in central Africa and SEA. Figure 11a and b displays changes in sea-level surface pressure (SLP) between the SMK and the CTL simulations for the two RCMs and for the JAS period. A dipole pattern showing a cyclonic anomaly over SEA and an anticyclonic anomaly over Congo and Angola is obtained for both models, despite geographical differences over SEA. Over the continent, the regional patterns of SLP changes are quite consistent, even if the maxima of the positive anomaly over Angola is higher in ALADIN $(+50 \mathrm{~Pa})$ compared to RegCM $(+40 \mathrm{~Pa})$. The anticyclonic anomaly is related to changes in the lower tropospheric radiative budget which is induced by BBAs. As reported for the air temperature changes, lower troposphere cooling (associated with heating above $4 \mathrm{~km}$ ) generally increases the stratification over the continent. This results in a more stable atmosphere and a decrease in vertical velocity between the surface and 4-5 km (Fig. 12). This impact of BBAs over the continent is consistent with results obtained by Sakaeda et al. (2011) and Allen and Sherwood (2010). The latter indicates an increase in lower tropospheric dry static stability over central Africa during the JJA period based on the NCAR CAM3 GCM coupled model. More recently, Allen et al. (2019) have also reported a general increase in LCF and lower tropospheric stability (estimated between $700 \mathrm{hPa}$ and the surface) over central Africa using three different GCMs.

Over SEA, the two vertical velocity transects (Fig. 12) indicate that the subsidence is reduced, with maxima located between 2 and $4 \mathrm{~km}$, which is consistent with Sakaeda et al. (2011) findings. Adebiyi et al. (2015) also indicate that ERAI subsidence is lower when there is more smoke aerosol present. The decrease in the tropospheric stability in both RCMs is likely due to the anomalous radiative heating in the aerosol layer (see Fig. 9) that enhances buoyancy. This is associated with a cyclonic circulation anomaly over most of the SEA and a low pressure anomaly of $\sim 30-40 \mathrm{~Pa}$ at the sea surface (Fig. 11a and b). This anomaly creates a change in the Sc cloud tops in the SMK simulation with, in particular, an increase of $\sim 30 \mathrm{hPa}$ (Fig. S5). Over SEA, the difference between the two models is more pronounced than over the continent, and the negative anomaly SLP is located further west and south in RegCM and is found to be lower $(-10$ to $-20 \mathrm{~Pa})$ than in ALADIN $(-30 \mathrm{hPa})$. The decrease in SST in RegCM results in a local enhancement of stability, quite similar to those produced over the continent, especially near the coast where the AOD is high. Some differences also appear near the Angolan coast, where RegCM simulations indicate an increase in the SLP $(\sim 20 \mathrm{~Pa})$, which is not simulated by ALADIN. As mentioned previously, the difference is due to a significant decrease in SST $(\sim-1.5 \mathrm{~K})$ in RegCM due to the BBA dimming effect near the Angolan coast (see Fig. 7a). Over this specific region, the results obtained by RegCM are in agreement with those of Sakaeda et al. (2011), who report an increase in the lower tropospheric stability over a large part of SEA due to BBA direct and semi-direct effects.

This SLP anomaly creates some changes in the surface wind speed and direction as shown by Fig. 11c and d. Over SEA in the ALADIN model, the negative cyclonic anomaly generates more westerly winds over the Gulf of Guinea $(\sim$ $0.4-0.5 \mathrm{~m} \mathrm{~s}^{-1}$ ) and increases the north wind along the coasts 

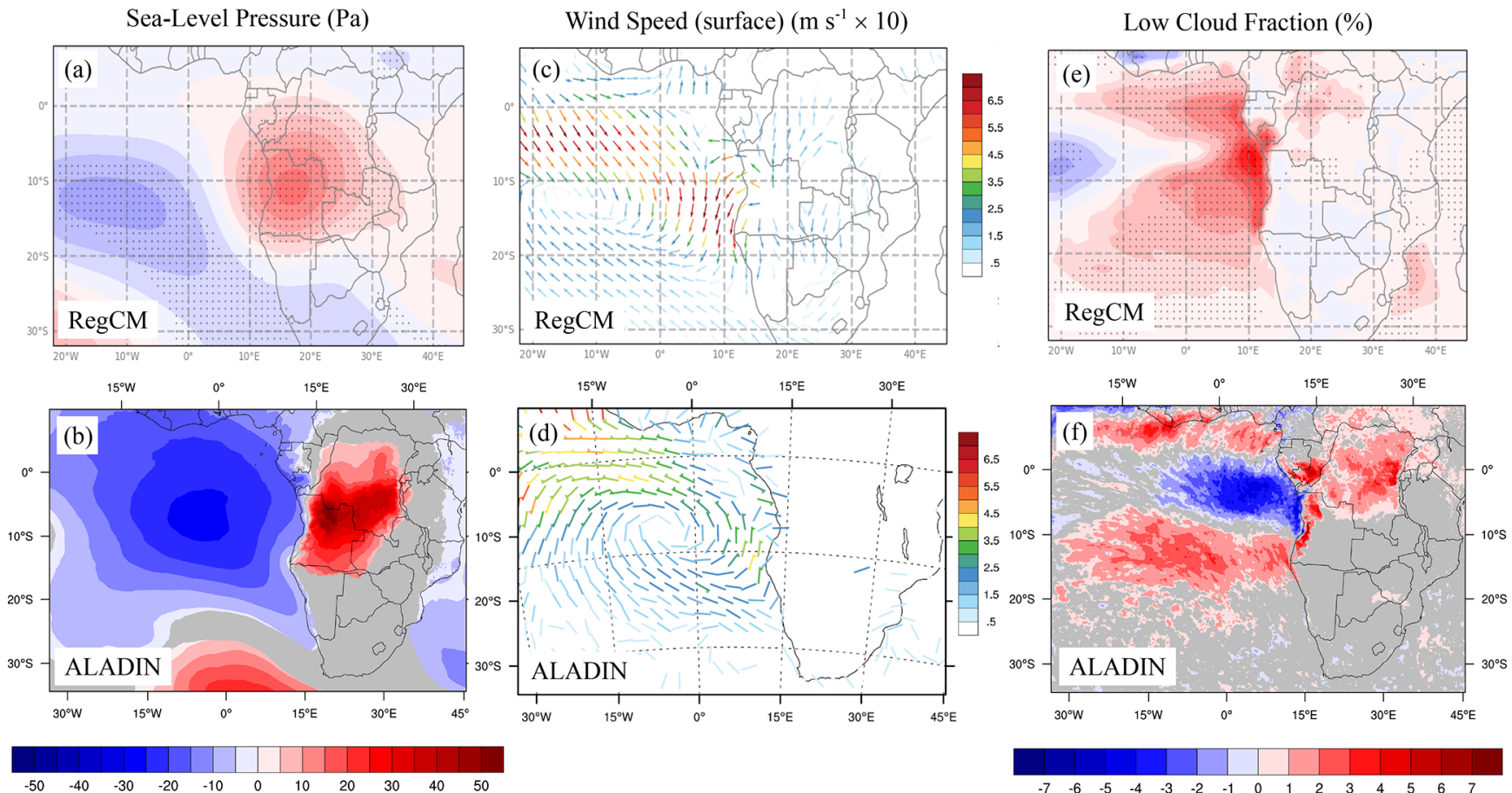

Figure 11. (a, b) Seasonal-mean (JAS) changes (SMK minus CTL simulations) in the sea-level pressure (SLP in Pa) for the ALADIN (b, period 2000-2015) and RegCM (a, period 2003-2015) models. (c, d) Seasonal-mean (JAS) changes in the surface wind speed. (e, f) Seasonalmean (JAS) changes in the LCF. The grey areas in ALADIN maps (not dashed in RegCM maps) are not statistically significant at the 0.05 level.

(a) Vertical Velocity / Liquid water - 6S / JAS 2000-2015

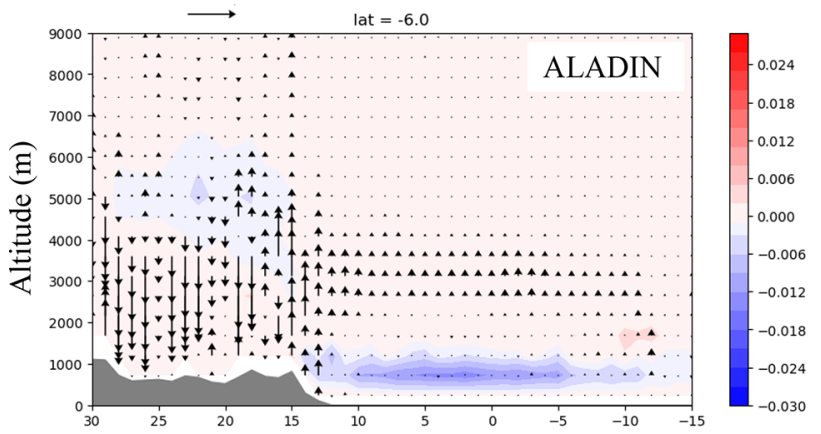

(b) Vertical Velocity / Liquid water - 12S / JAS 2000-2015

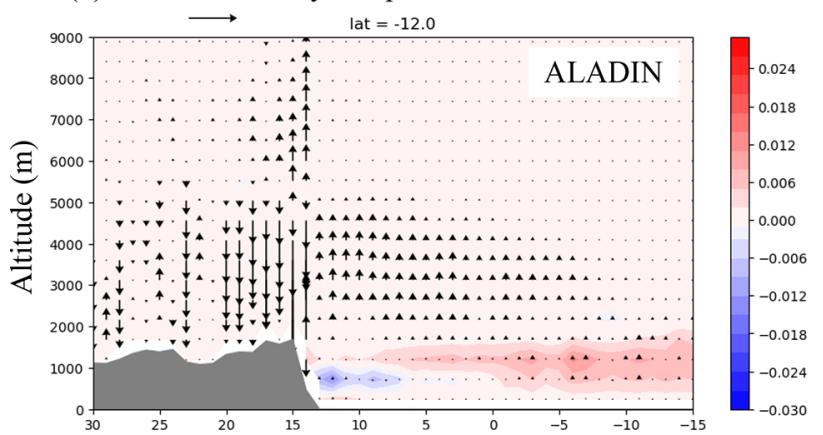

(c) Vertical Velocity / Liquid water - 6S / JAS 2003-2015

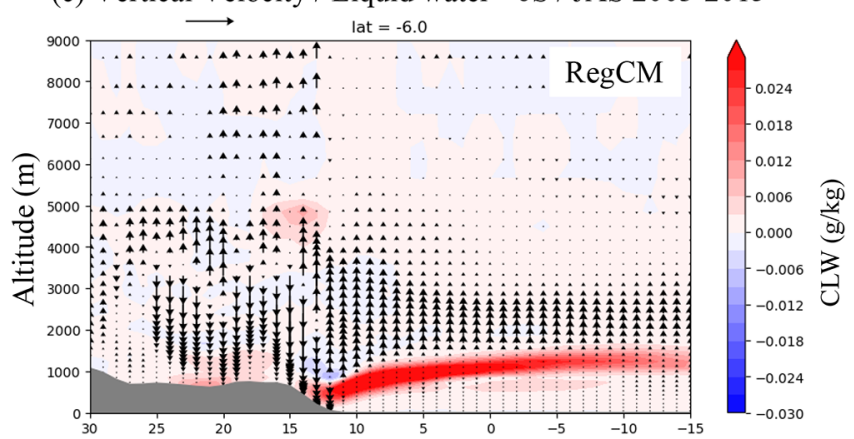

(d) Vertical Velocity / Liquid water - 12S / JAS 2003-2015

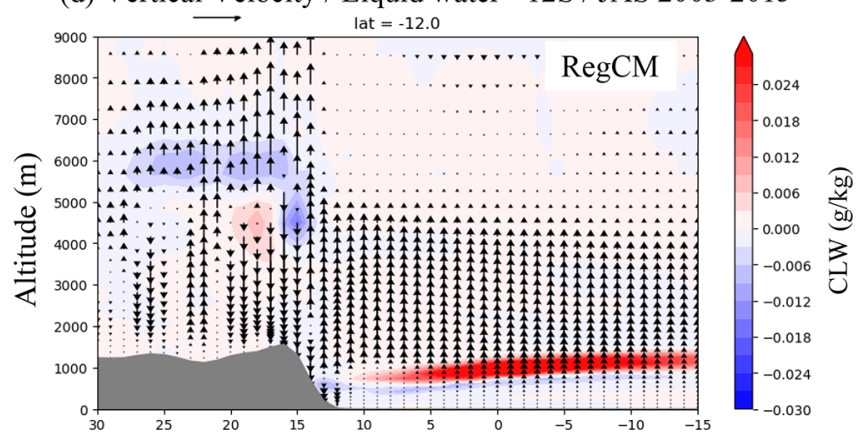

Figure 12. Seasonal-mean (JAS) changes (SMK minus CTL simulations) in the vertical profiles of the vertical velocity (arrow) and cloud liquid water content (in grams per kilogram) for ALADIN (a, b, period 2000-2015) and RegCM (c, d, period 2003-2015). 
of Angola and Congo by $\sim 0.3 \mathrm{~m} \mathrm{~s}^{-1}$. In the RegCM model due to the position of the anomaly, the changes in the wind fields are slightly different and an intensification of northwest winds (by $\sim 0.6 \mathrm{~m} \mathrm{~s}^{-1}$ ) between 0 and $10^{\circ} \mathrm{S}$ is simulated. Moreover, the increase in northerly winds near the coast of Angola detected in ALADIN is more pronounced in RegCM and reaches values of $\sim 0.6-0.7 \mathrm{~m} \mathrm{~s}^{-1}$.

\subsection{Impacts on Sc properties}

In addition to the SDE of BBAs on SLP and the atmospheric surface circulation, the impacts on Sc properties have been analyzed and are shown in Figs. 11e, $\mathrm{f}$ and 12. Over the continent, both RCMs simulate an increase in LCF and LWP associated with enhanced lower tropospheric stability as discussed previously. In ALADIN, the increase in LCF maxima $(\sim 7 \%)$ are located over Gabon and eastern Congo. More generally over Congo, the LCF is increased by about $2 \%-5 \%$. RegCM also produces higher LCF induced by BBAs, but the impact is generally lower, at $\sim 1 \%-2 \%$. These results are similar to those recently found by Allen et al. (2019), who report a $5 \%$ increase in LCF induced by fine aerosols using different GCMs (CAM4, CAM5 and GFDL). However, Sakaeda et al. (2011) report a decrease in the continental LCF. Reasons for this discrepancy would require a more detailed model intercomparison. Figure 11 also indicates a general increase in LCF along the Gulf of Guinea coast for the two RCMs, which is consistent with the recent work of Deetz et al. (2018), who indicate a negative feedback of the stratus-to-cumulus transition with increased aerosols during the DACCIWA experiment.

Over SEA, the LCF response pattern is quite different between the RCMs. While marked regional heterogeneous changes appear in ALADIN, a more uniform increase in LCF is obtained in RegCM. Nevertheless, Fig. 11c and d indicate that the sign of the LCF changes is consistent between the two RCM over the main Sc zone $\left(10-20^{\circ} \mathrm{S}, 0-10^{\circ} \mathrm{E}\right)$, indicating a moderate increase of $\sim 2 \%-5 \%$. This increase is also shown in Fig. 2a where there is a moderate increase in LCF $(\sim 2 \%-4 \%)$ in the SMK ALADIN and RegCM simulations compared to the CTL runs over box_O. Concerning the microphysical properties of Sc, Fig. $2 b$ indicates similar results for the LWP (over the box_O) with an increase of $\sim 6 \%-7 \%$ for ALADIN and $\sim 10 \%$ for RegCM. This is also clearly indicated in Fig. 12 for the transect at $12^{\circ} \mathrm{S}$, showing an increase in the cloud liquid water content (by $\sim+0.01 / 0.04 \mathrm{~g} \mathrm{~kg}^{-1}$ ) over the ocean in both models. The general increase in LCF and LWP over the Sc region is certainly due to an enhanced buoyancy above the MBL due to BBA SW heating, limiting the entrainment of dry air from the free troposphere within the marine boundary layer, as proposed by Wilcox (2010) and Johnson et al. (2004). This impact can be clearly seen in Fig. 12, which shows a reduced large-scale subsidence over the ocean for the two transects at 6 and $12^{\circ} \mathrm{S}$, as mentioned earlier.
North of $10^{\circ} \mathrm{S}$, ALADIN simulates a decrease in LCF contrary to RegCM. The negative impact obtained in ALADIN could be due to the decrease in latent heat fluxes (see Fig. S6) in the SMK simulation over this region, which limits humidity input in the MBL. The difference between the two models is also clearly shown in Fig. 12 for the transect at $6^{\circ} \mathrm{S}$, where a decrease in the liquid water content (of $\sim-0.01 \mathrm{~g} \mathrm{~kg}^{-1}$ ) appears in ALADIN over the ocean. At the same latitude, RegCM indicates on the contrary an increase in the water content of $\sim+0.04 \mathrm{~g} \mathrm{~kg}^{-1}$.

Compared to recent literature, the decrease in LCF simulated by ALADIN is found to be consistent with recent findings of Zhang and Zuidema (2019), who report a low-cloud cover decrease with enhanced smoke loadings at Ascension Island $\left(8^{\circ} \mathrm{S}, 14.5^{\circ} \mathrm{W}\right)$. In addition, the north-south gradient in the LCF changes obtained in ALADIN is remarkably consistent with the recent findings of Allen et al. (2019), showing similar impacts for 2 of the 3 GCMs used in their study. For the CAM4 and GFDL models, the radiative impact of finemode aerosols leads to a regional pattern of increased and decreased LCF over SEA, similar to that found in ALADINClimat. On the contrary, these changes in LCF differ from Sakaeda et al. (2011), who indicate a more uniform positive impact (increase in LCF) over SEA in agreement with the RegCM simulations. At this stage, it seems that the use of an atmosphere coupled to a slab ocean leads to more uniform responses (positive cloud feedback over most of the SEA) compared to atmospheric models only (using prescribed SST) such as ALADIN and Allen et al. (2019). The increase in the LCF over the ocean generally creates a negative semidirect effect at TOA over the SEA (Fig. S7), especially for the RegCM model. The values are between -2 and $-10 \mathrm{~W} \mathrm{~m}^{-2}$, slightly higher that the mean value $\left(-3.0 \mathrm{~W} \mathrm{~m}^{-2}\right)$ reported by Sakaeda et al. (2011) over SEA at a climatic scale. For the ALADIN model, positive and negative semi-direct forcing is present over the ocean due to different changes in the LCF. Finally, the positive semi-direct forcing over the continent is mainly related to the response of high clouds in both models.

\section{Sensitivity of the direct and semi-direct effect to smoke-absorbing properties}

In this section, the sensitivity of the different BBA impacts to smoke-absorbing properties have been tested using the ALADIN model. As mentioned earlier, two additional simulations (referred to as SMK_75 and SMK_90) were performed for the same period (2000-2015) where the smoke SSA has been changed to 0.75 and 0.90 , respectively. Figure 13 displays the DRE of BBAs exerted at TOA (in all-sky conditions) for the three different ALADIN runs. Over the continent, as expected, the results indicate an increase in the cooling effect of BBAs at TOA $\left(\sim-10\right.$ to $\left.-15 \mathrm{~W} \mathrm{~m}^{-2}\right)$ for the more scattering simulation (SMK_90). The opposite is 


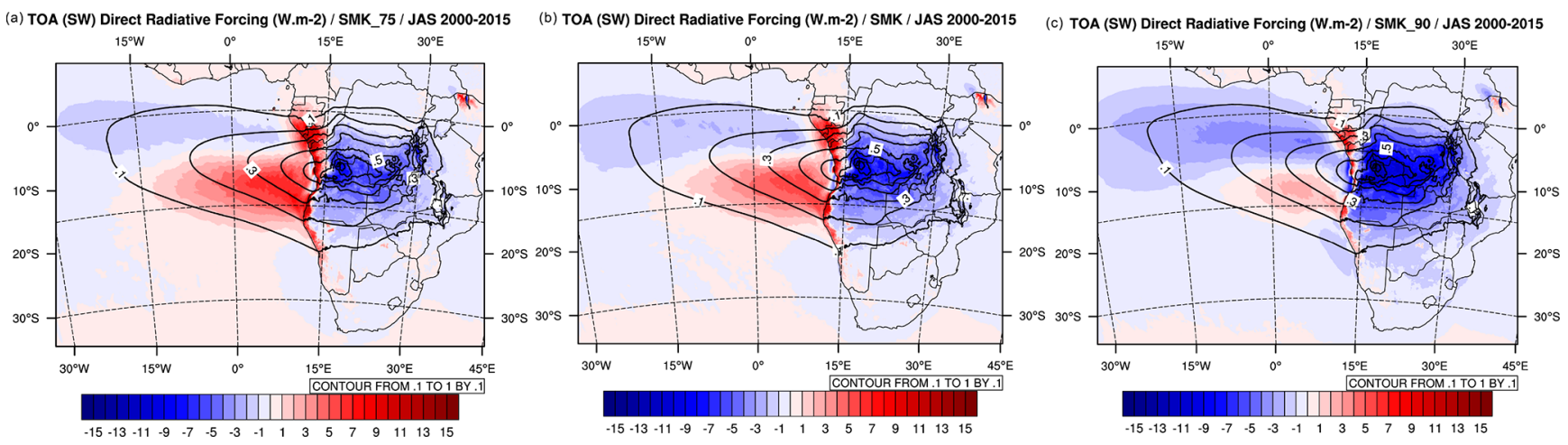

Figure 13. Seasonal-mean (JAS) BBA DRE $\left(\mathrm{W} \mathrm{m}^{-2}\right.$ ) at TOA exerted in the shortwave (all-sky conditions) for the three ALADIN simulations (SSA of $0.75, \mathbf{a} ; 0.85, \mathbf{b}$ and $0.90, \mathbf{c}$ ) and for the period 2000-2015. The AOD of BBAs are indicated by the black lines.

obtained for SMK_75, in which the DRE significantly decreases to $\sim-3$ to $-6 \mathrm{~W} \mathrm{~m}^{-2}$ over the continent. As the AOD over the continent remains constant between the different ALADIN simulations over the main BBA sources (Fig. 4), these significant changes in the TOA DRE are mainly due to the different absorbing properties and related adjustments. Notably, for the SMK_75 simulation, the large DRE changes at TOA compared to the SMK and SMK_90 simulations are also related to an increase in the LCF in SMK_75 (see Fig. S8), as well as the enhanced absorbing efficiency of BBAs. Both the aerosol surface dimming effect and the tropospheric radiative heating are enhanced in the case of SMK_75 compared to SMK and SMK_90 (not shown). This results in additional stratification and low-level clouds over the continent in SMK_75 (Fig. S8). The higher LCF increases the planetary albedo beneath the aerosol layers, which, combined with strongly absorbing smoke, significantly decreases the DRE of BBAs at TOA over central Africa compared to the CTL or SMK_90 runs (Fig. 13). Contrarily, SMK_90 is characterized by lower LCF, resulting in more significant cooling at TOA. These results highlight the complex feedbacks between BBAs and low-cloud properties modulating the DRE of smoke aerosols at TOA over central Africa.

Over SEA, Fig. 13 indicates considerable variability in the DRE at TOA among the three different simulations. As expected, the DRE exerted at TOA by BBAs over the Sc zone is greatly increased in the SMK_75 simulation compared to the SMK or SMK_90 and reaches values of $\sim+5-$ $10 \mathrm{~W} \mathrm{~m}^{-2}$ during the JAS season. The changes are quantified in Fig. S9, which shows the JAS DRE over box_O for each simulation. DRE varies from $+0.94 \mathrm{~W} \mathrm{~m}^{-2}$ for SMK_90 to $+3.93 \mathrm{~W} \mathrm{~m}^{-2}$ for SMK_75. Changes in the DRE at TOA are less significant when comparing the SMK and SMK_75 runs, with values of +3.21 and $+3.93 \mathrm{~W} \mathrm{~m}^{-2}$, respectively. Over the Gulf of Guinea, changes in the DRE exerted at TOA are opposite, and as expected the DRE increases in the SMK_90 simulation, when BBA scattering is enhanced. Over a darker ocean, compared to the Sc region, BBAs induce a cooling effect at TOA which is enhanced for higher SSA, reaching a maximum of about $-5 \mathrm{~W} \mathrm{~m}^{-2}$. The cooling increase at TOA for higher SSA could also be amplified by the moderate decrease in LCF found in the SMK_90 simulation, which results in a lower planetary albedo over the Gulf of Guinea (see Fig. S8) and a more negative TOA forcing.

\section{Conclusions}

This modeling study presents an analysis of the DRE and SDE of absorbing BBAs over the southeastern Atlantic using decadal simulations from two different regional climate models. ALADIN uses prescribed sea surface temperatures, while RegCM includes a slab ocean model. Both RCMs struggle to represent the LCF over SEA, which is a recurring problem in climate models (Nam et al., 2012), but the integrated liquid water content is fairly well modeled. This leads to uncertainties in the estimated DRE. For the JAS season, the simulated ALADIN and RegCM AODs are found to be consistent with the MERRA-2 and CAMS-RA reanalyses, contrary to the simulated ACAOD, which is slightly underestimated compared to satellite data for the two models. The DRE exerted at the surface by BBAs is significant in both models and varies regionally between -10 and $-50 \mathrm{~W} \mathrm{~m}^{-2}$, having significant impacts on continental and ocean surface temperatures. At TOA, the simulations indicate a remarkable SW DRE regional contrast in all-sky conditions for both models, in agreement with the recent MACv2 aerosol climatology. The TOA DRE is positive and $\sim+3-6 \mathrm{~W} \mathrm{~m}^{-2}$ over the Sc region. This important dipole over SEA is created by the transport of absorbing BBAs over both low and high LCFs.

ALADIN and RegCM simulations indicate that BBAs are responsible for an additional SW radiative heating of $\sim$ $+0.5-1 \mathrm{~K}$ by day over SEA during JAS, with maxima located at an altitude between 2 and $4 \mathrm{~km}$. The changes in the air temperature profile are shown to inhibit subsidence over SEA, 
creating a cyclonic anomaly at the sea-level pressure. The opposite effect (anticyclonic anomaly) is simulated over the continent by both models due to the increase in lower troposphere stability. Regarding the SDE of BBAs on low clouds, both models moderately increase LCF by $\sim 5 \%$ over the Sc region but their impacts differ over the Gulf of Guinea. These differences in SDE are likely due to the ocean-atmosphere coupling in RegCM only where changes in SSTs increase lower troposphere stability and LCF over SEA.

Two additional ALADIN simulations have been performed with different SSAs $(0.75$ and 0.90 at $550 \mathrm{~nm})$ and indicate that the DRE and SDE are sensitive to the absorbing properties of smoke. Over central Africa, feedbacks between BBAs and low-cloud properties, and so the surface albedo, contribute, in addition to the intrinsic absorbing properties of smoke, to modulating the DRE at TOA. Over the Sc region, the positive DRE is significantly increased for lower SSA simulations, with moderate SDE changes on low clouds. All the identified changes induced by BBA radiative effect on latent heat fluxes, lower troposphere atmospheric circulation and SST could possibly impact regional precipitation and dynamics (western African monsoon system) and need to be investigated in the future.

Data availability. All the ALADIN and RegCM model outputs could be provided upon request. MODIS data are available from the NASA Level 1 and Atmosphere Archive and Distribution System Distributed Active Archive Center at https://ladsweb.modaps.eosdis.nasa.gov/ (last access: April 2020) (NASA's Goddard Space Flight Center, 2020a). MODIS abovecloud data products are available from the authors upon request. The CALIOP L2 data are available on NASA Earth Science Data: https://earthdata.nasa.gov/ (last access: April 2020) (NASA Langley Research Center, 2020). ACAOD from POLDER (https://doi.org/10.25326/82, ICARE, 2020) could be obtained at https://www.icare.univ-lille.fr/aero-ac/ (last access: April 2020) (ICARE, 2020). MACv2 datasets are accessible at ftp://ftp-projects.zmaw.de/aerocom/climatology/MACv2_2018/ (last access: April 2020) (Max Planck, 2020). Cloud products have been obtained from the CM_SAF dataset (https://www.cmsaf.eu/EN/Products/AvailableProducts/Climate_ Data_recordsClimate_Data_Records_node.html, last access: April 2020) (EUMETSAT, 2020). Shortwave radiation PIRATA data are available at https://www.pmel.noaa.gov/tao/drupal/disdel/ (last access: April 2020) (Global Tropical Moored Buoy Array, 2020). Further information can be found on the CRU website for the CRU temperature and precipitation data set (http://www.cru.uea.ac.uk/data, last access: April 2020) (Climatic Research Unit, 2020), on the AERONET website for AERONET AOD data (https://aeronet.gsfc.nasa.gov/ (last access: April 2020) (NASA's Goddard Space Flight Center, 2020b).

Supplement. The supplement related to this article is available online at: https://doi.org/10.5194/acp-20-13191-2020-supplement.
Author contributions. MMa, PN, NE and FS have performed the ALADIN and RegCM simulations. PN, RR and MMi developed the ALADIN model. FW, DB, AMS and KM participated in providing different aerosol and cloud satellite products. PZ, CF, JR, PF and all co-authors participated in the analysis of all observations and model simulations. MMa finalized the paper with contributions from all co-authors.

Competing interests. The authors declare that they have no conflict of interest.

Special issue statement. This article is part of the special issue "New observations and related modelling studies of the aerosolcloud-climate system in the southeast Atlantic and southern Africa regions (ACP/AMT inter-journal SI)". It is not associated with a conference.

Acknowledgements. This work was supported by the French National Research Agency under grant agreement no. ANR-15-CE010014-01; the French national program LEFE/INSU; the Programme national de Télédetection Spatiale (PNTS, http://www.insu.cnrs. fr/pnts, last access: April 2020), grant no. PNTS-2016-14; the French National Agency for Space Studies (CNES, AEROCLIM and EECLAT projects); and the South African National Research Foundation (NRF) under grant UID 105958. The research leading to these results has received funding from the European Union's 7th Framework Programme (FP7/2014-2018) under EUFAR2 contract no. 312609. For the RegCM simulations, granted access to the HPC resources of CALMIP supercomputing center under the allocation 2019- p19062. We acknowledge all the principal investigators of the AERONET and PIRATA stations. We would like also to thank the NASA Langley Research Center Atmospheric Science Data Center, the National Center for Atmospheric Research and the Climate Research Unit for providing the data sets used to evaluate our climate simulations.

Financial support. This research has been supported by the French National Research Agency (grant no. ANR-15-CE01-0014-01), the French national program LEFE/INSU, the Programme national de Télédetection Spatiale (grant no. PNTS-2016-14), the French National Agency for Space Studies (CNES, AEROCLIM and EECLAT projects), and the South African National Research Foundation (NRF) (grant no. UID 105958). The research leading to these results has received funding from the European Union's 7th Framework Programme (grant no. FP7/2014-2018) under EUFAR2 (grant no. 312609). For the RegCM simulations, access was granted to the HPC resources of CALMIP supercomputing center under the allocation 2019- p19062.

Review statement. This paper was edited by Joshua Fu and reviewed by two anonymous referees. 


\section{References}

Abel, S. J., Haywood, J. M., Highwood, E. J., Li, J., and Buseck, P.R.: Evolution of biomass burning aerosol properties from an agricultural fire in southern Africa, Geophys. Res. Lett., 30, 1783, https://doi.org/10.1029/2002GL017342, 2003.

Ackerman, S., O. B. Toon, D. E. Stevens, A. J. Heymsfield, V. Ramanathan, and Welton, E. J.: Reduction of tropical cloudiness, Science, 288, 1042-1047, https://doi.org/10.1126/science.288.5468.1042, 2000.

Adebiyi, A. A., Zuidema, P., and Abel, S. J.: The convolution of dynamics and moisture with the presence of shortwave absorbing aerosols over the southeast Atlantic, J. Climate, 28, 1997-2024, https://doi.org/10.1175/JCLI-D-14-00352.1, 2015.

Allen, R. J. and Sherwood, S. C.: Aerosol cloud semi-direct effect and land-sea temperature contrast in a GCM, Geophys. Res. Lett., 37, L07702, https://doi.org/10.1029/2010GL042759, 2010.

Allen, R. J., Amiri-Farahani, A., Lamarque, J. F., Smith, C., Shindell, D., Hassan, T., and Chung, C. E.: Observationally constrained aerosol-cloud semi-direct effects, npj Clim. Atmos. Sci., 2, 16, https://doi.org/10.1038/s41612-019-0073-9, 2019.

Andreae, M. O. and Merlet, P.: Emission of trace gases and aerosols from biomass burning, Global Biogeochem. Cy., 15, 955-966, 2001

Benas, N., Finkensieper, S., Stengel, M., van Zadelhoff, G.J., Hanschmann, T., Hollmann, R., and Meirink, J. F.: The MSGSEVIRI-based cloud property data record CLAAS-2, Earth Syst. Sci. Data, 9, 415-434, https://doi.org/10.5194/essd-9-4152017, 2017.

Bollasina, M. A., Ming, Y., Ramaswamy, V., Schwarzkopf, M. D., and Naik, V.: Contribution of local and remote anthropogenic aerosols to the twentieth century weakening of the South Asian Monsoon, Geophys. Res. Lett., 41, 680-687, https://doi.org/10.1002/2013GL058183, 2014.

Bougeault, P.: Modeling the Trade-Wind Cumulus Boundary Layer. Part I: Testing the Ensemble Cloud Relations Against Numerical Data, J. Atmos. Sci., 38, 2414-2428, 1981.

Bourlès, B., Araujo, M., McPhaden, M. J., Brandt, P., Foltz, G. R., Lumpkin, R., Giordani, H., Hernandez, F., Lefèvre, N., Nobre, P., Campos, E., Saravanan, R., Trotte-duhà, J., Dengler, M., Hahn, J., Hummels, R., Lübbecke, J. F., Rouault, M., Cotrim, L., Sutton, A., Jochum, M., and Perez, R. C.: PIRATA: A sustained observing system for tropical Atlantic climate research and forecasting, Earth Space Sci., 6, 577-616, https://doi.org/10.1029/2018EA000428, 2019.

Brient F., Roehrig, R., and Voldoire, A.: Evaluating marine stratocumulus clouds in the CNRM-CM6-1 model using shortterm hindcasts, J. Adv. Model. Earth Syst., 11, 127-148, https://doi.org/10.1029/2018MS001461, 2019.

Climatic Research Unit: Data, available at: http://www.cru.uea.ac. uk/data, last access: April 2020.

Cuxart, J., Bougeault, P., and Redelsperger, J. L.: A turbulence scheme allowing for mesoscale and large-eddy simulations, Q. J. Roy. Meteorol. Soc., 126, 1-30, https://doi.org/10.1002/qj.49712656202, 2000.

Darbyshire, E., Morgan, W. T., Allan, J. D., Liu, D., Flynn, M. J., Dorsey, J. R., O'Shea, S. J., Lowe, D., Szpek, K., Marenco, F., Johnson, B. T., Bauguitte, S., Haywood, J. M., Brito, J. F., Artaxo, P., Longo, K. M., and Coe, H.: The vertical distribution of biomass burning pollution over tropical South Amer- ica from aircraft in situ measurements during SAMBBA, Atmos. Chem. Phys., 19, 5771-5790, https://doi.org/10.5194/acp19-5771-2019, 2019.

Das, S., Harshvardhan, H., Bian, H., Chin, M., Curci, G., Protonotariou, A. P., Mielonen, T., Zhang, K., Wang, H., and Liu, X.: Biomass burning aerosol transport and vertical distribution over the South African-Atlantic region, J. Geophys. Res.-Atmos., 122, 6391-6415, https://doi.org/10.1002/2016JD026421, 2017.

Deaconu, L. T., Ferlay, N., Waquet, F., Peers, F., Thieuleux, F., and Goloub, P.: Satellite inference of water vapour and abovecloud aerosol combined effect on radiative budget and cloudtop processes in the southeastern Atlantic Ocean, Atmos. Chem. Phys., 19, 11613-11634, https://doi.org/10.5194/acp-19-116132019, 2019.

Decharme, B., Delire, C., Minvielle, M., Colin, J., Vergnes, J.-P., Alias, A., Saint-Martin, D., Séférian, R., Sénési, S., and Voldoire, A.: Recent changes in the ISBA-CTRIP land surface system for use in the CNRM-CM6 climate model and in global off-line hydrological applications. J. Adv. Model. Earth Syst., 11, $1207-$ 1252, https://doi.org/10.1029/2018MS001545, 2019.

Dee, D. P., Uppala, S. M., Simmons, A. J., Berrisford, P., Poli, P., Kobayashi, S., Andrae, U., Balmaseda, M. A., Balsamo, G., Bauer, P., Bechtold, P., Beljaars, A. C. M., van de Berg, L., Bidlot, J., Bormann, N., Delsol, C., Dragani, R., Fuentes, M., Geer, A. J., Haimbergere, L., Healy, S. B., Hersbach, H., Hólm, E. V., Isaksen, L., Kallberg, P., Köhler, M., Matricardi, M., McNally, A. P., Monge-Sanzf, B. M., Morcrette, J.-J., Park, B.-K., Peubey, C., de Rosnaya, P., Tavolato, C., Thépaut, J.-N., and Vitart, F.: The ERA-Interim reanalysis: configuration and performance of the data assimilation system, Q. J. Roy. Meteorol. Soc., 137, 553597, https://doi.org/10.1002/qj.828, 2011.

Deetz, K., Vogel, H., Knippertz, P., Adler, B., Taylor, J., Coe, H., Bower, K., Haslett, S., Flynn, M., Dorsey, J., Crawford, I., Kottmeier, C., and Vogel, B.: Numerical simulations of aerosol radiative effects and their impact on clouds and atmospheric dynamics over southern West Africa, Atmos. Chem. Phys., 18, 9767-9788, https://doi.org/10.5194/acp-18-9767-2018, 2018.

Denjean, C., Bourrianne, T., Burnet, F., Mallet, M., Maury, N., Colomb, A., Dominutti, P., Brito, J., Dupuy, R., Sellegri, K., Schwarzenboeck, A., Flamant, C., and Knippertz, P.: Overview of aerosol optical properties over southern West Africa from DACCIWA aircraft measurements, Atmos. Chem. Phys., 20, 4735-4756, https://doi.org/10.5194/acp-20-4735-2020, 2020.

Dubovik, O. and King, M. D.: A flexible inversion algorithm for retrieval of aerosol optical properties from Sun and sky radiance measurements, J. Geophys. Res., 105, 20673-20696, https://doi.org/10.1029/2000JD900282, 2000.

Dubovik, O., Holben, B., Eck, T. F., Smirnov, A., Kaufman, Y. J., King, M. D., Tanre, D., and Slutsker, I.: Variability of Absorption and Optical Properties of Key Aerosol Types Observed in Worldwide locations, J. Atmos. Sci., 59, 590-608, 2002.

Eck, T. F., Holben, B. N., Reid, J. S., Mukelabai, M. M., Piketh, S. J., Torres, O., Jethva, H. T., Hyer, E. J., Ward, D. E., Dubovik, O., Sinyuk, A., Schafer, J. S., Giles, D. M., Sorokin, M., Smirnov, A., and Slutsker, I.: A seasonal trend of single scattering albedo in southern African biomass-burning particles: Implications for satellite products and estimates of emissions for the world's largest biomass-burning source, J. Geophys. Res.-Atmos., 118, 6414-6432, https://doi.org/10.1002/jgrd.50500, 2013. 
EUMETSAT: CM SAF, Climate monitoring, available at: https://www.cmsaf.eu/EN/Products/AvailableProducts/Climate_ Data_recordsClimate_Data_Records_node.html, last access: April 2020.

Fierce, L., Bond, T. C., Bauer, S. E., Mena, F., and Riemer, N.: Black carbon absorption at the global scale is affected by particle-scale diversity in composition, Nat. Commun., 7, 12361, https://doi.org/10.1038/ncomms12361, 2016.

Flamant, C., Knippertz, P., Fink, A. H., Akpo, A., Brooks, B., Chiu, C. J., Coe, H., Danuor, S., Evans, M., Jegede, O., Kalthoff, N., Konaré, A., Liousse, C., Lohou, F., Mari, C., Schlager, H., Schwarzenboeck, A., Adler, B., Amekudzi, L., Aryee, J., Ayoola, M., Batenburg, A. M., Bessardon, G., Borrmann, S., Brito, J., Bower, K., Burnet, F., Catoire, V., Colomb, A., Denjean, C., Fosu-Amankwah, K., Hill, P. G., Lee, J., Lothon, M., Maranan, M., Marsham, J., Meynadier, R., Ngamini, J.-B., Rosenberg, P., Sauer, D., Smith, V., Stratmann, G., Taylor, J. W., Voigt, C., and Yoboué, V.: The Dynamics-Aerosol-ChemistryCloud Interactions in West Africa field campaign: Overview and research highlights, B. Am. Meteorol. Soc., 99, 83-104, https://doi.org/10.1175/BAMS-D-16-0256.1, 2018.

Foltz, G. R., Evan, A. T., Freitag, H. P., Brown, S., and McPhaden, M. J.: Dust accumulation biases in PIRATA shortwave radiation records, J. Atmos. Ocean. Tech., 30, 1414-1432, https://doi.org/10.1175/JTECH-D-12-00169.1, 2013.

Formenti, P., D’Anna, B., Flamant, C., Mallet, M., Piketh, S. J., Schepanski, K., Waquet, F., Auriol, F., Brogniez, G., Burnet, F., Chaboureau, J.-P., Chauvigné, A., Chazette, P., Denjean, C., Desboeufs, K., Doussin, J.-F., Enguidi, N., Feuerstein, S., Gaetani, M., Giorio, C., Klopper, D., Mallet, M. D., Nabat, P., Monod, A., Solmon, F., Namwoonde, A., Chikwililwa, C., Mushi, R., Welton, E. J., and Holben, B.: The Aerosols, Radiation and Clouds in southern Africa (AEROCLOsA) field campaign in Namibia: overview, illustrative observations and way forward, B. Am. Meteorol. Soc., 100, 1277-1298, https://doi.org/10.1175/BAMS-D17-0278.1, 2019.

Ghan, S. J.: Technical Note: Estimating aerosol effects on cloud radiative forcing, Atmos. Chem. Phys., 13, 9971-9974, https://doi.org/10.5194/acp-13-9971-2013, 2013.

Giorgi, F., Coppola, E., Solmon, F., Mariotti, L., Sylla, M., Bi, X., Elguindi, N., Diro, G. T., Nair, V., Giuliani, G., Turuncoglu, U. U., Cozzini, S., Güttler, I., O’Brien, T. A., Tawfik, A. B., Shalaby, A., Zakey, A. S., Steiner, A. L., Stordal, F., Sloan, L. C., and Brankovic, C.: RegCM4: model description and preliminary tests over multiple CORDEX domains, Clim. Res., 52, 7-29, 2012.

Global Tropical Moored Buoy Array: PIRATA, available at: https: //www.pmel.noaa.gov/tao/drupal/disdel/, last access: April 2020.

Gordon, H., Field, P. R., Abel, S. J., Dalvi, M., Grosvenor, D. P., Hill, A. A., Johnson, B. T., Miltenberger, A. K., Yoshioka, M., and Carslaw, K. S.: Large simulated radiative effects of smoke in the south-east Atlantic, Atmos. Chem. Phys., 18, 15261-15289, https://doi.org/10.5194/acp-18-15261-2018, 2018.

Grythe, H., Ström, J., Krejci, R., Quinn, P., and Stohl, A.: A review of seaspray aerosol source functions using a large global set of sea salt aerosol concentration measurements, Atmos. Chem. Phys., 14, 1277-1297, https://doi.org/10.5194/acp-141277-2014, 2014.

Hansen, J., Sato, M., and Ruedy, R.: Radiative forcing and climate response, J. Geophys. Res., 102, 6831-6864, 1997.
Harris, I., Jones, P., Osborn, T., and Lister, D.: Updated high-resolution grids of monthly climatic observations the cru ts3.10 dataset, Int. J. Climatol., 34, 623-642, https://doi.org/10.1002/joc.3711, 2013.

Herbert, R. J., Bellouin, N., Highwood, E. J., and Hill, A. A.: Diurnal cycle of the semi-direct effect from a persistent absorbing aerosol layer over marine stratocumulus in large-eddy simulations, Atmos. Chem. Phys., 20, 1317-1340, https://doi.org/10.5194/acp-20-1317-2020, 2020.

ICARE: AERIS, available at: https://www.icare.univ-lille.fr/ aero-ac/ (last access: April 2020) or https://doi.org/10.25326/82, 2020.

Inness, A., Ades, M., Agustí-Panareda, A., Barré, J., Benedictow, A., Blechschmidt, A.-M., Dominguez, J. J., Engelen, R., Eskes, H., Flemming, J., Huijnen, V., Jones, L., Kipling, Z., Massart, S., Parrington, M., Peuch, V.-H., Razinger, M., Remy, S., Schulz, M., and Suttie, M.: The CAMS reanalysis of atmospheric composition, Atmos. Chem. Phys., 19, 3515-3556, https://doi.org/10.5194/acp-19-3515-2019, 2019.

Jiang, X., Waliser, D. E., Olson, W. S., Tao, W.-K., L'Ecuyer, T. S., Li, K.-F., Yung, Y. L., Shige, S., Lang, S., and Takayabu, Y. N.: Vertical diabatic heating structure of the MJO: Intercomparison between recent reanalyses and TRMM estimates, Mon. Weather Rev., 139, 3208-3233, 2011.

Johnson, B. T., Shine, K. P., and Forster, P. M.: The semi-direct aerosol effect: Impact of absorbing aerosols on marine stratocumulus, Q. J. Roy. Meteorol. Soc., 130, 1407-1422, 2004.

Johnson, B. T., Osborne, S. R., Haywood, J. M., and Harrison, M. A. $\mathrm{J}$.: Aircraft measurements of biomass burning aerosol over West Africa during DABEX, J. Geophys. Res.-Atmos., 113, D00C06, https://doi.org/10.1029/2007JD009451, 2008.

Johnson, B. T., Haywood, J. M., Langridge, J. M., Darbyshire, E., Morgan, W. T., Szpek, K., Brooke, J. K., Marenco, F., Coe, H., Artaxo, P., Longo, K. M., Mulcahy, J. P., Mann, G. W., Dalvi, M., and Bellouin, N.: Evaluation of biomass burning aerosols in the HadGEM3 climate model with observations from the SAMBBA field campaign, Atmos. Chem. Phys., 16, 1465714685, https://doi.org/10.5194/acp-16-14657-2016, 2016.

Kacenelenbogen, M. S., Vaughan, M. A., Redemann, J., Young, S. A., Liu, Z., Hu, Y., Omar, A. H., LeBlanc, S., Shinozuka, Y., Livingston, J., Zhang, Q., and Powell, K. A.: Estimations of global shortwave direct aerosol radiative effects above opaque water clouds using a combination of A-Train satellite sensors, Atmos. Chem. Phys., 19, 4933-4962, https://doi.org/10.5194/acp19-4933-2019, 2019.

Kahn, R. A. and Gaitley, B. J.: An analysis of global aerosol type as retrieved by MISR, J. Geophys. Res.-Atmos., 120, 4248-4281, https://doi.org/10.1002/2015JD023322, 2015.

Kahn, R. A., Gaitley, B. J., Garay, M. J., Diner, D. J., Eck, T. F., Smirnov, A., and Holben, B. N.: Multiangle Imaging SpectroRadiometer global aerosol product assessment by comparison with the Aerosol Robotic Network, J. Geophys. Res., 115, D23209, https://doi.org/10.1029/2010JD014601, 2010.

Keil, A. and Haywood, J. M.: Solar radiative forcing by biomass burning aerosol particles during SAFARI 2000: A case study based on measured aerosol and cloud properties, J. Geophys. Res., 108, 8467, https://doi.org/10.1029/2002JD002315, 2003. 
Kinne, S.: Aerosol radiative effects with MACv2, Atmos. Chem. Phys., 19, 10919-10959, https://doi.org/10.5194/acp-19-109192019, 2019.

Klein, S. and Hartmann, D.: The seasonal cycle of low stratiform clouds, J. Climate, 6, 1587-1606, 1993.

Koch, D. and Del Genio, A. D.: Black carbon semi-direct effects on cloud cover: review and synthesis, Atmos. Chem. Phys., 10, 7685-7696, https://doi.org/10.5194/acp-10-7685-2010, 2010.

Labonne, M., Breon, F.-M., and Chevallier, F.: Injection height of biomass burning aerosols as seen from a spaceborne lidar, Geophys. Res. Lett., 34, L11806, https://doi.org/10.1029/2007GL029311, 2007.

Laprise, R., Hernández-Díaz, L., Tete, K., Sushama, L., Šeparović, L., Martynov, A., Winger, K., and Valin, M.: Climate projections over CORDEX Africa domain using the fifth-generation Canadian Regional Climate Model (CRCM5), Clim. Dynam., 41, 3219-3246, https://doi.org/10.1007/s00382-012-1651-2, 2013.

Lau, K. M., Kim, M. K., and Kim, K. M.: Asian monsoon anomalies induced by aerosol direct effects, Clim. Dynam., 26, 855- 864, 2006.

Lau, K. M., Kim, K. M., Sud, Y. C., and Walker, G. K.: A GCM study of the response of the atmospheric water cycle of West Africa and the Atlantic to Saharan dust radiative forcing, Ann. Geophys., 27, 4023-4037, https://doi.org/10.5194/angeo27-4023-2009, 2009.

Leahy, L. V., Anderson, T. L., Eck, T. F., and Bergstrom, R. W.: A synthesis of single scattering albedo of biomass burning aerosol over southern Africa during SAFARI 2000, Geophys. Res. Lett., 34, L12814, https://doi.org/10.1029/2007GL029697, 2007.

Lu, Z., Liu, X., Zhang, Z., Zhao, C., Meyer, K., Rajapakshe, C., Wu, C., Yang, Z., and Penner, J. E.: Biomass smoke from southern Africa can significantly enhance the brightness of stratocumulus over the southeastern Atlantic Ocean, P. Natl. Acad. Sci. USA, 115, 2924-2929, https://doi.org/10.1073/pnas.1713703115, 2018.

Malavelle, F., Pont, V., Mallet, M., Solmon, F., Johnson, B., Leon, J.-F., and Liousse, C.: Simulation of aerosol radiative effects over West Africa during DABEX and AMMA SOP-0, J. Geophys. Res., 116, D08205, https://doi.org/10.1029/2010JD014829, 2011.

Mallet, M., Solmon, F., Roblou, L., Peers, F., Turquety, S., Waquet, F., Jethva, H., and Torres, O.: Simulation of Optical Properties and Direct and Indirect Radiative Effects of Smoke Aerosols Over Marine Stratocumulus Clouds During Summer 2008 in California With the Regional Climate Model RegCM, J. Geophys. Res.-Atmos., 122, 10288-10313, 2017.

Mallet, M., Nabat, P., Zuidema, P., Redemann, J., Sayer, A. M., Stengel, M., Schmidt, S., Cochrane, S., Burton, S., Ferrare, R., Meyer, K., Saide, P., Jethva, H., Torres, O., Wood, R., Saint Martin, D., Roehrig, R., Hsu, C., and Formenti, P.: Simulation of the transport, vertical distribution, optical properties and radiative impact of smoke aerosols with the ALADIN regional climate model during the ORACLES-2016 and LASIC experiments, Atmos. Chem. Phys., 19, 4963-4990, https://doi.org/10.5194/acp19-4963-2019, 2019.

Marlier, M. E., DeFries, S. R., Voulgarakis, A., Kinney, P. L., Randerson, J. T., Shindell, D. T., Chen, Y., and Faluvegi, G.: El Nino and health risks from landscape fire emis- sions in southeast Asia, Nat. Clim. Change, 3, 131-136, https://doi.org/10.1038/nclimate1658, 2013.

Marticorena, B. and Bergametti, G.: Modeling the atmosphere dust cycle: 1. Design of a soil-derived dust emission scheme, J. Geophys. Res., 100, 16415-16430, 1995.

Masson, V., Le Moigne, P., Martin, E., Faroux, S., Alias, A., Alkama, R., Belamari, S., Barbu, A., Boone, A., Bouyssel, F., Brousseau, P., Brun, E., Calvet, J.-C., Carrer, D., Decharme, B., Delire, C., Donier, S., Essaouini, K., Gibelin, A.-L., Giordani, H., Habets, F., Jidane, M., Kerdraon, G., Kourzeneva, E., Lafaysse, M., Lafont, S., Lebeaupin Brossier, C., Lemonsu, A., Mahfouf, J.-F., Marguinaud, P., Mokhtari, M., Morin, S., Pigeon, G., Salgado, R., Seity, Y., Taillefer, F., Tanguy, G., Tulet, P., Vincendon, B., Vionnet, V., and Voldoire, A.: The SURFEXv7.2 land and ocean surface platform for coupled or offline simulation of earth surface variables and fluxes, Geosci. Model Dev., 6, 929-960, https://doi.org/10.5194/gmd-6-929-2013, 2013.

Max Planck: Aerosol Climatology version 2, MACv2, available at: ftp://ftp-projects.zmaw.de/aerocom/climatology/MACv2_2018/, last access: April 2020.

Menut, L., Flamant, C., Turquety, S., Deroubaix, A., Chazette, P., and Meynadier, R.: Impact of biomass burning on pollutant surface concentrations in megacities of the Gulf of Guinea, Atmos. Chem. Phys., 18, 2687-2707, https://doi.org/10.5194/acp18-2687-2018, 2018.

Meyer, K., Platnick, S., and Zhang, Z.: Simultaneously inferring above-cloud absorbing aerosol optical thickness and underlying liquid phase cloud optical and microphysical properties using MODIS, J. Geophys. Res.-Atmos., 119, 5104-5114, https://doi.org/10.1002/2013JD021053, 2015.

Michou, M., Nabat, P., and Saint-Martin, D.: Development and basic evaluation of a prognostic aerosol scheme (v1) in the CNRM Climate Model CNRM-CM6, Geosci. Model Dev., 8, 501-531, https://doi.org/10.5194/gmd-8-501-2015, 2015.

Michou, M., Nabat, P., Saint-Martin, D., Bock, J., Decharme, B., Mallet, M., Roehrig, R., Séférian, R., Sénési, S., and Voldoire, A.: Present-day and historical aerosol and ozone characteristics in CNRM CMIP6 simulations, J. Adv. Model. Earth Syst., 12, e2019MS001816, https://doi.org/10.1029/2019MS001816, 2020.

Mlawer, E. J., Taubman, S. J., Brown, P. D., Iacono, M. J., and Clough, S. A.: Radiative transfer for inhomogeneous atmospheres: RRTM, a validated correlated- $k$ model for the longwave, J. Geophys. Res., 102, 16663-16682, https://doi.org/10.1029/97JD00237, 1997.

Morcrette, J. J.: Description of the radiation scheme in the ECMWF model, Tech. rep., ECMWF, 1989.

Nabat, P., Somot, S., Mallet, M., Michou, M., Sevault, F., Driouech, F., Meloni, D., di Sarra, A., Di Biagio, C., Formenti, P., Sicard, M., Léon, J.-F., and Bouin, M.-N.: Dust aerosol radiative effects during summer 2012 simulated with a coupled regional aerosol-atmosphere-ocean model over the Mediterranean, Atmos. Chem. Phys., 15, 3303-3326, https://doi.org/10.5194/acp15-3303-2015, 2015.

Nabat, P., Somot, S., Cassou, C., Mallet, M., Michou, M., Bouniol, D., Decharme, B., Drugé, T., Roehrig, R., and SaintMartin, D.: Modulation of radiative aerosols effects by atmospheric circulation over the Euro-Mediterranean region, Atmos. 
Chem. Phys., 20, 8315-8349, https://doi.org/10.5194/acp-208315-2020, 2020.

Nam, C., Bony, S., Dufresne, J.-L., and Chepfer, H.: The "too few, too bright" tropical low-cloud problem in CMIP5 models, Geophys. Res. Lett., 39, L21801, https://doi.org/10.1029/2012GL053421, 2012.

NASA's Goddard Space Flight Center: LAADS DAAC, available at: https://ladsweb.modaps.eosdis.nasa.gov/ (last access: April 2020), 2020a.

NASA's Goddard Space Flight Center: DRAGON FIREXAQ, available at: https://aeronet.gsfc.nasa.gov/ (last access: April 2020), 2020b.

NASA Langley Research Center: EOSDIS DAACs, available at: https://earthdata.nasa.gov/, last access: April 2020.

O’Brien, T. A., Chuang, P. Y., Sloan, L. C., Faloona, I. C., and Rossiter, D. L.: Coupling a new turbulence parametrization to RegCM adds realistic stratocumulus clouds, Geosci. Model Dev., 5, 989-1008, https://doi.org/10.5194/gmd-5-989-2012, 2012.

Pan, X., Ichoku, C., Chin, M., Bian, H., Darmenov, A., Colarco, P., Ellison, L., Kucsera, T., da Silva, A., Wang, J., Oda, T., and Cui, G.: Six global biomass burning emission datasets: intercomparison and application in one global aerosol model, Atmos. Chem. Phys., 20, 969-994, https://doi.org/10.5194/acp-20-9692020, 2020.

Peers, F., Waquet, F., Cornet, C., Dubuisson, P., Ducos, F., Goloub, P., Szczap, F., Tanré, D., and Thieuleux, F.: Absorption of aerosols above clouds from POLDER/PARASOL measurements and estimation of their direct radiative effect, Atmos. Chem. Phys., 15, 4179-4196, https://doi.org/10.5194/acp15-4179-2015, 2015.

Perlwitz, J. P. and Miller, R. L.: Cloud cover increase with increasing aerosol absorptivity - A counterexample to the conventional semi-direct aerosol effect, J. Geophys. Res., 115, D08203, https://doi.org/10.1029/2009JD012637, 2010.

Petrenko, M., Kahn, R., Chin, M., Soja, A., Kucsera, T., and Harshvardhan, N.: The use of satellite-measured aerosol optical depth to constrain biomass burning emissions source strength in the global model GOCART, J. Geophys. Res., 117, D18212, https://doi.org/10.1029/2012JD017870, 2012.

Philippon, N., Cornu, G., Monteil, L., Gond, V., Moron, V., Pergaud, J., Sèze, G., Bigot, S., Camberlin, P., Doumenge, C., Fayolle, A., and Ngomanda, A.: The light-deficient climates of western Central African evergreen forests, Environ. Res. Lett., 14, 034007, https://doi.org/10.1088/1748-9326/aaf5d8, 2019.

Pistone, K., Redemann, J., Doherty, S., Zuidema, P., Burton, S., Cairns, B., Cochrane, S., Ferrare, R., Flynn, C., Freitag, S., Howell, S. G., Kacenelenbogen, M., LeBlanc, S., Liu, X., Schmidt, K. S., Sedlacek III, A. J., Segal-Rozenhaimer, M., Shinozuka, Y., Stamnes, S., van Diedenhoven, B., Van Harten, $\mathrm{G}$., and $\mathrm{Xu}, \mathrm{F}$.: Intercomparison of biomass burning aerosol optical properties from in situ and remote-sensing instruments in ORACLES-2016, Atmos. Chem. Phys., 19, 9181-9208, https://doi.org/10.5194/acp-19-9181-2019, 2019.

Ramanathan, V., Crutzen, P., Lelieveld, J., Mitra, A., Althausen, D., Anderson, J., Andreae, M., Cantrell, W., Cass, G., Chung, C., Clarke, A., Coakley, J., Collins, W., Conant, W., Dulac, F., Heintzenberg, J., Heymsfield, A., Holben, B., Howell, S., Hudson, J., Jayaraman, A., Kiehl, J., Krishnamurti, T., Lubin, D., Mcfarquhar, G., Novakov, T., Ogren, J., Podgorny, I., Prather, K.,
Priestley, K., Prospero, J., Quinn, P., Rajeev, K., Rasch, P., Rupert, S., Sadourny, R., Satheesh, S., Shaw, G. A., Sheridan, P., and Valero, F.: Indian Ocean Experiment: An integrated analysis ofthe climate forcing and effects of the great Indo-Asian haze, J. Geophys. Res., 106, 28371-28398, 2001.

Randles, C. A. and Ramaswamy, V.: Direct and semi-direct impacts of absorbing biomass burning aerosol on the climate of southern Africa: a Geophysical Fluid Dynamics Laboratory GCM sensitivity study, Atmos. Chem. Phys., 10, 9819-9831, https://doi.org/10.5194/acp-10-9819-2010, 2010.

Randles, C. A., da Silva, A. M., Buchard, V., Colarco, P. R., Darmenov, A., Govindaraju, R., Smirnov, A., Holben, B., Ferrare, R., Hair, J., Shinozuka, Y., and Flynn, C. J.: The MERRA2 aerosol reanalysis, 1980 onward. Part I: System description and data assimilation evaluation, J. Climate, 30, 6823-6850, https://doi.org/10.1175/JCLI-D-16-0609.1, 2017.

Reddington, C. L., Spracklen, D. V., Artaxo, P., Ridley, D. A., Rizzo, L. V., and Arana, A.: Analysis of particulate emissions from tropical biomass burning using a global aerosol model and long-term surface observations, Atmos. Chem. Phys., 16, 1108311106, https://doi.org/10.5194/acp-16-11083-2016, 2016.

Redemann, J., Wood, R., Zuidema, P., Doherty, S. J., Luna, B., LeBlanc, S. E., Diamond, M. S., Shinozuka, Y., Chang, I. Y., Ueyama, R., Pfister, L., Ryoo, J., Dobracki, A. N., da Silva, A. M., Longo, K. M., Kacenelenbogen, M. S., Flynn, C. J., Pistone, K., Knox, N. M., Piketh, S. J., Haywood, J. M., Formenti, P., Mallet, M., Stier, P., Ackerman, A. S., Bauer, S. E., Fridlind, A. M., Carmichael, G. R., Saide, P. E., Ferrada, G. A., Howell, S. G., Freitag, S., Cairns, B., Holben, B. N., Knobelspiesse, K. D., Tanelli, S., L’Ecuyer, T. S., Dzambo, A. M., Sy, O. O., McFarquhar, G. M., Poellot, M. R., Gupta, S., O'Brien, J. R., Nenes, A., Kacarab, M. E., Wong, J. P. S., Small-Griswold, J. D., Thornhill, K. L., Noone, D., Podolske, J. R., Schmidt, K. S., Pilewskie, P., Chen, H., Cochrane, S. P., Sedlacek, A. J., Lang, T. J., Stith, E., Segal-Rozenhaimer, M., Ferrare, R. A., Burton, S. P., Hostetler, C. A., Diner, D. J., Platnick, S. E., Myers, J. S., Meyer, K. G., Spangenberg, D. A., Maring, H., and Gao, L.: An overview of the ORACLES (ObseRvations of Aerosols above CLouds and their intEractionS) project: aerosol-cloud-radiation interactions in the Southeast Atlantic basin, Atmos. Chem. Phys. Discuss., https://doi.org/10.5194/acp-2020-449, in review, 2020.

Rissler, J., Vestin, A., Swietlicki, E., Fisch, G., Zhou, J., Artaxo, P., and Andreae, M. O.: Size distribution and hygroscopic properties of aerosol particles from dry-season biomass burning in Amazonia, Atmos. Chem. Phys., 6, 471-491, https://doi.org/10.5194/acp-6-471-2006, 2006.

Roehrig, R., Beau, I., Saint Martin, D., Alias, A., Decharme, B., Guérémy, J. F., Voldoire, A., Ahmat Younous, A.-L., Bazile, E., Belamari, S., Blein, S., Bouniol, D., Bouteloup, Y., Cattiaux, J., Chauvin, F., Chevallier, M., Colin, J., Douville, H., Marquet, P., Michou, M., Nabat, P., Oudar, T., Peyrillé, P., Piriou, J.M., Salas y Melia, D., Séférian, R., and Sénési, S.: The CNRM global atmosphere model ARPEGE Climat 6.3: Description and evaluation, J. Adv. Model. Earth Syst., 12, e2020MS002075, https://doi.org/10.1029/2020MS002075, 2020.

Sakaeda, N., Wood, R., and Rasch, P. J.: Direct and semidirect aerosol effects of southern African biomass burning aerosol, J. Geophys. Res., 116, D12205, https://doi.org/10.1029/2010JD015540, 2011. 
Sayer, A. M., Hsu, N. C., Bettenhausen, C., Lee, J., Redemann, J., Schmid, B., and Shinozuka, Y.: Extending "Deep Blue" aerosol retrieval coverage to cases of absorbing aerosols above clouds: Sensitivity analysis and first case studies, J. Geophys. Res.-Atmos., 121, 4830-4854, https://doi.org/10.1002/2015JD024729, 2016.

Sayer, A. M., Hsu, N. C., Lee, J., Kim, W. V., Burton, S., Fenn, M. A., Ferrare, R. A., Kacenelenbogen, M., LeBlanc, S., Pistone, K., Redemann, J., Segal-Rozenhaimer, M., Shinozuka, Y., and Tsay, S.-C.: Two decades observing smoke above clouds in the south-eastern Atlantic Ocean: Deep Blue algorithm updates and validation with ORACLES field campaign data, Atmos. Meas. Tech., 12, 3595-3627, https://doi.org/10.5194/amt12-3595-2019, 2019.

Seethala, C., Meirink, J. F., Horváth, Á., Bennartz, R., and Roebeling, R.: Evaluating the diurnal cycle of South Atlantic stratocumulus clouds as observed by MSG SEVIRI, Atmos. Chem. Phys., 18, 13283-13304, https://doi.org/10.5194/acp-18-132832018, 2018.

Shinozuka, Y., Saide, P. E., Ferrada, G. A., Burton, S. P., Ferrare, R., Doherty, S. J., Gordon, H., Longo, K., Mallet, M., Feng, Y., Wang, Q., Cheng, Y., Dobracki, A., Freitag, S., Howell, S. G., LeBlanc, S., Flynn, C., Segal-Rosenhaimer, M., Pistone, K., Podolske, J. R., Stith, E. J., Bennett, J. R., Carmichael, G. R., da Silva, A., Govindaraju, R., Leung, R., Zhang, Y., Pfister, L., Ryoo, J.-M., Redemann, J., Wood, R., and Zuidema, P.: Modeling the smoky troposphere of the southeast Atlantic: a comparison to ORACLES airborne observations from September of 2016, Atmos. Chem. Phys., 20, 11491-11526, https://doi.org/10.5194/acp-20-11491-2020, 2020.

Sogacheva, L., Popp, T., Sayer, A. M., Dubovik, O., Garay, M. J., Heckel, A., Hsu, N. C., Jethva, H., Kahn, R. A., Kolmonen, P., Kosmale, M., de Leeuw, G., Levy, R. C., Litvinov, P., Lyapustin, A., North, P., Torres, O., and Arola, A.: Merging regional and global aerosol optical depth records from major available satellite products, Atmos. Chem. Phys., 20, 2031-2056, https://doi.org/10.5194/acp-20-2031-2020, 2020.

Solmon, F., Giorgi, F., and Liousse, C.: Aerosol modelling for regional climate studies: application to anthropogenic particles and evaluation over a European/African domain, Tellus B, 58, 51-72, 2006.

Solmon, F., Mallet, M., Elguindi, N., Giorgi, F., Zakey, I., and Konaré, A.: Dust impact on sahelian precipitation gradients, mechanisms and sensitivity to absorption properties, Geophys. Res. Lett., 35, L24705, https://doi.org/10.1029/2008GL035900, 2008.

Solmon, F., Elguindi, N., and Mallet, M.: Evaluation of dust aerosol climatic impacts over West Africa as simulated by a regional climate model, Clim. Res., 52, 97-113, 2012.

Solmon, F., Nair, V. S., and Mallet, M.: Increasing Arabian dust activity and the Indian summer monsoon, Atmos. Chem. Phys., 15, 8051-8064, https://doi.org/10.5194/acp-15-8051-2015, 2015.

Sommeria, G. and Deardorff, J. W.: Subgrid-Scale Condensation in Models of Nonprecipitating Clouds, J. Atmos. Sci., 34, 344-355, 1977.

Stier, P., Schutgens, N. A. J., Bellouin, N., Bian, H., Boucher, O., Chin, M., Ghan, S., Huneeus, N., Kinne, S., Lin, G., Ma, X., Myhre, G., Penner, J. E., Randles, C. A., Samset, B., Schulz, M., Takemura, T., Yu, F., Yu, H., and Zhou, C.: Host model uncer- tainties uncertainties in aerosol radiative forcing estimates: results from the Aero-Com Prescribed intercomparison study, Atmos. Chem. Phys., 13, 3245-3270, https://doi.org/10.5194/acp13-3245-2013, 2013.

Stjern, C., Samset, B. H., Myhre, G., Forster, P. M., Hodnebrog, Ø., Andrews, T., Boucher, O., Faluvegi, G., Iversen, T., Kasoar, M., Kharin, V., Kirkevåg, A., Lamarque, J.-F., Olivié, D., Richardson, T., Shawki, D., Shindell, D., Smith, C. J., Takemura, T., and Voulgarakis, A.: Rapid adjustments cause weak surface temperature response to increased black carbon concentrations, J. Geophys. Res.-Atmos., 122, 11462-11481, https://doi.org/10.1002/2017JD027326, 2017.

Thornhill, G. D., Ryder, C. L., Highwood, E. J., Shaffrey, L. C., and Johnson, B. T.: The effect of South American biomass burning aerosol emissions on the regional climate, Atmos. Chem. Phys., 18, 5321-5342, https://doi.org/10.5194/acp-185321-2018, 2018.

Tosca, M. G., Randerson, J. T., and Zender, C. S.: Global impact of smoke aerosols from landscape fires on climate and the Hadley circulation, Atmos. Chem. Phys., 13, 5227-5241, https://doi.org/10.5194/acp-13-5227-2013, 2013.

Tosca, M. G., Diner, D. J., Garay, M. J., and Kalashnikova, O. V.: Human-caused fires limit convection in tropical Africa: First temporal observations and attribution, Geophys. Res. Lett., 42, 6492-6501, https://doi.org/10.1002/2015GL065063, 2015.

Tummon, F., Solmon, F., Liousse, C., and Tadross, M.: Simulation of the direct and semidirect aerosol effects on the southern Africa regional climate during the biomass burning season, J. Geophys. Res., 115, D19206, https://doi.org/10.1029/2009JD013738, 2010.

Vakkari, V., Beukes, J. P., Dal Maso, M., Aurela, M., Josipovic, M., and Van Zyl, P. G.: Major secondary aerosol formation in southern African open biomass burning plumes, Nat. Geosci., 11, 580-583, 2018.

van Marle, M. J. E., Kloster, S., Magi, B. I., Marlon, J. R., Daniau, A.-L., Field, R. D., Arneth, A., Forrest, M., Hantson, S., Kehrwald, N. M., Knorr, W., Lasslop, G., Li, F., Mangeon, S., Yue, C., Kaiser, J. W., and van der Werf, G. R.: Historic global biomass burning emissions for CMIP6 (BB4CMIP) based on merging satellite observations with proxies and fire models (1750-2015), Geosci. Model Dev., 10, 3329-3357, https://doi.org/10.5194/gmd-10-3329-2017, 2017.

Vaughan, M. A., Powell, K. A., Winker, D. M., Hostetler, C. A., Kuehn, R. E., Hunt, W. H., Getzewich, B. J., Young, S. A., Liu, Z., and McGill, M. J.: Fully automated detection of cloud and aerosol layers in the CALIPSO lidar measurements, J. Atmos. Ocean. Tech., 26, 2034-2050, 2009.

Waquet, F., Peers, F., Ducos, F., Goloub, P., Platnick, S., Riedi, J., Tanré, D., and Thieuleux, F.: Global analysis of aerosol properties above clouds, Geophys. Res. Lett., 40, 5809-5814, 2013.

Wilcox, E. M.: Stratocumulus cloud thickening beneath layers of absorbing smoke aerosol, Atmos. Chem. Phys., 10, 1176911777, https://doi.org/10.5194/acp-10-11769-2010, 2010.

Winker, D. M., Hunt, W. H., and McGill, M. J.: Initial performance assessment of CALIOP, Geophys. Res. Lett., 34, L19803, https://doi.org/10.1029/2007GL030135, 2007.

Wu, H., Taylor, J. W., Szpek, K., Langridge, J., Williams, P. I., Flynn, M., Allan, J. D., Abel, S. J., Pitt, J., Cotterell, M. I., Fox, C., Davies, N. W., Haywood, J., and Coe, H.: Vertical vari- 
ability of the properties of highly aged biomass burning aerosol transported over the southeast Atlantic during CLARIFY-2017, Atmos. Chem. Phys. Discuss., https://doi.org/10.5194/acp-2020197, in review, 2020.

Xu, H., Guo, J. P., Ceamanos, X., Roujean, J. L., Min, M., and Carrer, D.: On the influence of the diurnal variations of aerosol content to estimate direct aerosol radiative forcing using MODIS data, Atmos. Environ., 141, 186-196, https://doi.org/10.1016/j.atmosenv.2016.06.067, 2016.

Zakey, A. S., Giorgi, F., and Bi, X.: Modeling of sea salt in a regional climate model: Fluxes and radiative forcing, J. Geophys. Res., 113, D14221, https://doi.org/10.1029/2007JD009209, 2008.

Zhang, J. and Zuidema, P.: The diurnal cycle of the smoky marine boundary layer observed during August in the remote southeast Atlantic, Atmos. Chem. Phys., 19, 14493-14516, https://doi.org/10.5194/acp-19-14493-2019, 2019.
Zou, Y., Wang, Y., Qian, Y., Tian, H., Yang, J., and Alvarado, E.: Using CESM-RESFire to understand climate-fire-ecosystem interactions and the implications for decadal climate variability, Atmos. Chem. Phys., 20, 995-1020, https://doi.org/10.5194/acp20-995-2020, 2020.

Zuidema, P., Redemann, J., Haywood, J., Wood, R., Piketh, S. Hipondoka, M., and Formenti, P.: Smoke and clouds above the southeast Atlantic: Upcoming field campaigns probe absorbing aerosols impact on climate, B. Am. Meteorol. Soc., 97, 11311135, 2016.

Zuidema, P., Sedlacek, A., Flynn, C., Springston, S., Delgadillo, R., Zhang, J., Aiken, A., and Muradyan, P.: The Ascension Island boundary layer in the remote southeast Atlantic is often smoky, Geophys. Res. Lett., 45, 4456-4465, https://doi.org/10.1002/2017GL076926, 2018. 